\title{
"Be Gay, Do Crimes": The Co-Production and Activist Potential of Contemporary Fanzines
}

\author{
ALYSE MARIE ALLRED and COLIN M. GRAY, Purdue University, USA
}

Online creative communities are increasingly a space for marginalized groups to build solidarity and engage in activist work, encouraging the exploration and articulation of intersectionally-marginalized identities through processes of creative production. One such context for creative production includes community-driven sites such as Archive of Our Own, which by their design are intended to leverage and effectively support voices that are marginalized on other social platforms. In this paper, we build upon work on creative production and fan communities to further describe the work of fanart and fanzine collectives. We share the results of 1) an interview study with fanzine producers and 2) a two month remote co-design study where we further explored fanzine culture and the potential of future archival support. We used a range of qualitative methods to investigate themes of activism co-production in relation to the fanzine work of these producers, seeking to identify characteristic barriers and opportunities for community support as these artists seek to promote their work, encourage the co-production of work with other artists, and navigate the constantly shifting legal landscape associated with fanart. We conclude with implications for creative community support that amplify marginalized voices and facilitate archival work at the intersection of visual art, folksonomy, and legality.

CCS Concepts: • Human-centered computing $\rightarrow$ Collaborative and social computing design and evaluation methods; Empirical studies in collaborative and social computing.

Additional Key Words and Phrases: fanzine, codesign, fan fiction, fandom, collaborative computing

ACM Reference Format:

Alyse Marie Allred and Colin M. Gray. 2021. "Be Gay, Do Crimes": The Co-Production and Activist Potential of Contemporary Fanzines. Proc. ACM Hum.-Comput. Interact. 5, CSCW2, Article 376 (October 2021), 35 pages. https://doi.org/10.1145/3479520

\section{INTRODUCTION}

Social computing researchers are increasingly interested in describing how communities function, including articulating platform affordances that support community engagement and identifying the role that platforms play in the everyday functioning of these communities $[8,110]$. In the past decade, scholarship has also investigated the role of platforms in creating spaces for marginalized groups to organize and build solidarity [25,26], with some of these groups using the lens of creative production and participation to support the exploration and articulation of intersectionallymarginalized identities [29, 97].

Prior research has addressed the role of online creative communities in supporting creative production, with relevant strands of work that relate to crowdwork and creativity $[17,69,93]$, the formation and sustainment of online creative collaboration $[68,90]$, the use of online communities as a means of supporting identity formation in relation to creative work $[19,59,62,73,81]$, and the use of mentorship $[53,84]$ and critique $[19,62]$ practices as a means of performing and supporting

Authors' address: Alyse Marie Allred, allreda@purdue.edu; Colin M. Gray, gray42@purdue.edu, Purdue University, West Lafayette, IN, USA.

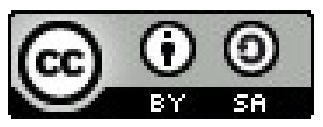

This work is licensed under a Creative Commons Attribution-ShareAlike International 4.0 License.

(C) 2021 Copyright held by the owner/author(s).

2573-0142/2021/10-ART376. https://doi.org/10.1145/3479520

Proc. ACM Hum.-Comput. Interact., Vol. 5, No. CSCW2, Article 376. Publication date: October 2021. 
creative production. Building on this work, there is an opportunity in CSCW scholarship to build awareness for alternate organizational structures and means of creative production. For example, many online communities engage in creative production outside of professional spaces. One focus of this emerging inquiry has been the community-driven site Archive of Our Own, which serves as both an archive for fanfic contributors and a means of supporting mentorship, organizational, and archival practices among community members $[14,18,43]$. We seek to build upon this increasing interest in fan communities in this paper, focusing on the fanart community, which is highly distributed due to relatively recent changes in individual platform policies that have disrupted archival practices and communication among members.

To frame the challenges faced by the fanart community in particular, we begin by describing the impact of one such policy change. In December 2018, Tumblr moved to ban all adult content from their microblogging platform. Until then, Tumblr had been considered something of a bastion for online transformative fandom-a demographic defined by Dym et. al as a "community of media fans that create and share works derivative/transformative of original media content" [29]. More importantly, transformative fandom has often been acknowledged as a safe space for marginalized groups-particularly women and queer folks. Tumblr was well suited for hosting and sharing visual artifacts, such as fanart, gift sets, and even videos, many of which delved into explicit explorations of feminine and queer identity and sexuality. As a result, the site policy change did not simply remove content, but gutted the cultural backbone of otherwise underrepresented groups.

From the outside, this policy change and its implementation was an algorithmically-flawed comedy of errors. Some fans, especially those familiar with similar policies that had caused them to leave other platforms, anticipated the impact of this policy change and left Tumblr before the policy went into effect. Those that remained bore witness to mass blog deletions and the indiscriminate erasure of fan content. Within months, Tumblr's usage had dropped by millions [46, 64]. Before the end of the year, Tumblr's parent company, Verizon, sold the site at almost a billion dollar loss [94]

Since no new platform has emerged to support these orphaned communities, fanartists have adapted a much older fandom practice to preserve their communities: fanzines. In the lead-up to and aftermath of the Tumblr porn ban, fanzines have not only reentered fandom spaces, but increasingly proliferated. While recent CSCW and fan studies scholarship has laid a conceptual groundwork for the study of fanart, we note that fanart communities have a different culture and set of social norms that intersect with other fan communities. For instance, fanart is a key component to fandom interactions, academically acknowledged as a form of legal tender in fandom's layered gift economy [50]. But unlike fanfiction writers, who have the protections of the Hugo Award winning repository, Archive of Our Own, fanartists lack a safety net. The situation resonates with the case study described by Jessa Lingel, whose research on digital countercultures examined the Brooklyn Drag scene, and how the inflexibility of Facebook's identification policy in the face of complex queer identity became hostile to Drag Queens who depended on the platform to develop their persona, broaden their networks, and expand their audience [66]. Thus, the story of Tumblr and the forced platform migration of the fanart community connects with broader concerns in CSCW scholarship, serving as an example of the power of platform policy decisions that impact certain types of users-in particular, those who are already marginalized-resulting in a massive loss of content while disrupting community participation. Using this forced migration as the beginning point for our study, we will describe how the fanart community built new means of resilience beyond the use of any one platform to support their creative production, demonstrating that even when support systems and platforms break, community engagement is still possible.

In this paper, we seek to describe the rich landscape of creative production within the context of fanart and fanzines, with a particular focus on roles, norms, and constraints that impact the past and current development of this community. We build upon the first author's direct involvement 
in this community over more than five years, describing the results of two interrelated studies: 1) an interview study with five fanzine producers who had successfully moderated a fanzine project, which we analyze as case studies; building upon the analysis of these interviews, we conducted 2) a co-design study with five established fanzine moderators using Discord, including a series of four activities completed collaboratively over a two-month period. Through qualitatively focused analysis within and across these studies which build upon the design framework of Archive of Our Own, we identify means of organizing visually-focused co-production work, characterize tools and methods used to organize these efforts, and identify complex challenges that result from these interactions.

Our contribution in this work to the CSCW literature is two-fold: First, we describe the complex community roles that emerge in the creation of fanart and fanzines through an interview study of fanzine moderators, extending prior work to reveal new archival considerations and community norms in creative production. Second, we identify desired community supports shared by our codesign participants to better facilitate distributed creative work, offering new ways of considering legal issues, moderation norms and categorization ontologies, and means of connecting creation, iteration, and monetization.

\section{RELATED WORK}

\subsection{On the Origin of Fanzines}

Fanzines, a portmanteau of "fan magazines," are approximately what their name describes: unofficial publications created and consumed by a community built on a shared interest. Although fanzines have existed across multiple interest groups, most notably the countercultural Punk Rock scene of the 1980s [39], the production of media-specific fanzines is nearly as old as modern media fandom, first appearing alongside physical fandom gatherings in the pre-internet era. These early homebrew fanzines were often little more than photocopied booklets stapled together by hand, and acted as an early method of long-distance communication between fans. With fanzines acting as a vehicle, information about fandom events and community news-and more importantly, fanfiction-was disseminated amongst fans in growing numbers [1]. As fandom communities continued to grow, fanzines continued to be a staple of fan interactions. Comic conventions would sometimes host Fanzine Reading Rooms, which gave fans space to peruse physical collections [32, 34], while fanzine producers poured time and effort into transforming their projects into semi-professional publications with wide readerships $[2,52,61]$. As their notoriety grew, fanzines eventually caught the attention of intellectual property (IP) holders, with mixed reactions. While for the most part, fanzines were politely tolerated or ignored by their IP holders, some did receive positive reception. Gene Roddenberry, creator of Star Trek, reportedly praised Spockanalia, the first Star Trek exclusive fanzine, going so far as to assigning it to new show writers as required reading [60]. However, these instances were few and far between and the tolerance most often ended with the queer and erotic, as was seen in the open letters on behalf of Lucasfilm to Star Wars fanzines, expressly forbidding homosexual and explicit heterosexual writings [35].

Although these censorship attempts were only the prelude to future conflicts between fans and IP holders, it was the internet itself that was most directly responsible for the eventual decline of fanzines [56]. Fans proved early adopters of the internet, utilizing it as a faster, cheaper, easier way to connect and share fanfiction with other fans from around the world. However, this new internet-enabled landscape saw continued attempts at censorship, from the ever-present threat of legal action from IP holders [55], to site-specific content purges, many of which continued to target queer and adult works [38]. Eventually these struggles coalesced into a small handful of fanfiction 
repositories, perhaps most importantly Archive of Our Own (AO3), which will be discussed at greater length later.

While fans fought for legitimacy in this new, electronic battleground, other efforts were undertaken to preserve archives of fanfiction through the fandom history wiki Fanlore. Although one or two fanzine reading rooms remain (e.g., [32]), they were at first replaced with fanzine lending libraries [22, 36, 99], which in turn became parts of academic archives [77, 98, 106, 107]. Although these collections are largely inaccessible to most fans, a quasi-equilibrium has been achieved thanks to the conscious effort that has seen fanfiction thrive in online spaces and become better protected in archived fanzines.

Yet, while it seemed that fanzines were now an artifact of bygone era, fanzine production saw a sudden resurgence in the mid-2010s. This new iteration, while still categorically "fanzines," diverges significantly from their predecessors, most prominently in their content. Instead of pages of written text, the new fanzines are colorfully filled with glossy, high-quality fan art prints. The physical fanzines also come with new enhancements, such as providing access to a digital copy, or the availability of physical merchandise such as keychains, lanyards, and enamel pins. The makeup of the project teams has changed as well, with single projects often boasting contributors from around the world. The broad availability of graphic design and publication software, paired with improved and democratized access to manufacturers, has elevated the level of professionalism in even smaller projects. The internet that was originally thought to have killed fanzines appears to have only led to their evolution.

\subsection{Fanfiction: The Beating Heart of Fan Studies}

Fanfiction lives at the heart of fandom, both as a key element for building and maintaining internal culture and as a recognizable artifact to outsiders. It provided the foundation for the academic understanding of transformative fandom, starting with the two foundational publications-Henry Jenkins Textual Poachers and Camille Bacon-Smith's Enterprising Women-both of which draw heavily from fanfiction and early print fanzines for their insights into fan culture [2,56]. This trend persists in more recent scholarship, such as Karen Hellekson's A Brief History of Media Fandom, which explicitly uses fanfiction as the measure for reporting and interpreting fannish history in a series of interconnected essays [52].

Fanfiction's large preoccupation with slash-the non-canon, queer romantic pairing of two characters from a piece of media-has also informed studies on the culture and history of transformative fandom, helping to define it as a space created by and for marginalized groups. Queer studies have examined how fandom is a "theater" for exploring queer identity by rewriting or recontextualizing existing narratives [27, 28, 45]. Feminist studies have explored how fandom is inherently a "gendered" space-a gift economy running in direct opposition to the masculine capitalistic mainstream $[50,51,105]$. Disability studies have also identified various attempts of fandom members to make content accessible to fans with a wide spectrum of abilities [5].

Equally important is how these subversions of existing commercial narratives have resulted in pushback from IP holders, who have variously perceived fan works as low-brow, derivative, or tainting the original. Legal censorship has marked fannish history with cease and desist letters, lawsuits, and a perpetual debate about copyright law and fair use [40, 102, 104]. To this day, "Anne Rice and Her Lawyers" remains a cultural bogeyman of fandom spaces, warning of the dangers of legal censorship [55]. More subtle forms of censorship also occur regularly, with fandom hubs such as Livejournal attempting to create "safer" environments by purging "offensive" material, which almost inevitably and disproportionately affects queer spaces [74]. A new threat posed to fan communities is the exploitation of fanfiction for capitalistic gain, in part due to the success of E.L. James rebranded fanfiction, Fifty Shades of Gray. The provision of online systems such as 
FanLib and Amazon's Kindle Worlds has tempted fanfiction authors with the promise of payment for their work, only for the corporations to disproportionately profit while also actively curating out listings that might be too subversive (i.e., queer) to be marketable $[23,103]$. These montetization attempts have largely failed, in part due to the work of fandom activist group the Organization for Transformative Works ${ }^{1}$, which formed in the aftermath a particularly prominent period of fandom censorship [43]. The development and impact of their Hugo Award Winning fanfiction hosting site, Archive of Our Own ${ }^{2}$, has enabled additional avenues of research on collective means of engaging in creative work [57].

Social computing has been one such beneficiary of Archive of Our Own's success. The foundational paper An Archive of Their Own presents AO3 as a standout case study of feminist design [43]. These design practices have been central in explorations of how and where fandom migrations occur [30, 42], and how fandoms implement a unique brand of teaching and mentorship $[18,33,44]$. Additionally, AO3 has been examined as a unique, democratically-run "rogue archive" [24], with metadata from the site generating insights into online archival practices and folksonomies $[14,15,58,108]$.

Outside of fanfiction, fanvidding (sometimes shortened to "vidding") has also received a fair amount of academic attention [48]. Fanvidding is a decades old fan practice pioneered by women, including the remixing of video clips and music clips with the intent to explore the characters, themes, and emotions of a particular piece of media [16]. Variations on fanvids include anime music videos (AMVs), which exclusively use Japanese anime for their source material, and machinima, which make use of video game character models to act out skits [54, 81]. Unlike fanfiction, though, fanvids have struggled to find a stable host site, especially as platforms such as YouTube become increasingly hostile towards fan creations and other remix works [21, 47]. As a result, the preservation of fanvids has become a more pressing issue, with initial probes looking to follow the model set by AO3 for archiving fanfiction [104].

\subsection{Return of the Zine: Fanart's Parallel History}

Although an important part of fandom's gift economy, fanart does not enjoy the same robust body of literature as other forms of fanwork we have discussed. This is perhaps in part because its concept and boundaries are more nebulous than either fanfiction or fanvidding. Fandom scholar Suzanne Scott describes fanart as encompassing "fan drawing and painting, as well as digital manipulations, mash-ups, and even potentially animated GIFs" [89]. The work of fanartists often pushes those boundaries as well, bleeding into other forms of fanwork. Fancomics, for instance, are generally considered a form of fanart, despite relying on written dialogue to facilitate longer-form stories in a way more akin to fanfiction. Similarly, fan animation is seen as another extension of fanart, despite sharing a video format and hosting platform with fanvids.

Despite these intersections and relevance to fandom research, fanart is sometimes dismissed outright in order to narrow the focus to better researched topics, most frequently fanfiction [52]. More often, though, fanart is mentioned only in passing, framed in vague "otherness" that sometimes exists to support fanfiction. Even studies into social norm formation in fandom spaces, which give fanart greater consideration than previous studies, still do so through the primary lens of fanfiction-specifically mentioning how the social taboo of charging money for fanfiction does not extend to fanart $[23,41]$.

The literature that does exist in this space reveals similarities between fanart and early fanfiction studies. Some scholars have taken on a feminist lens, examining and arguing for the validity of

\footnotetext{
${ }^{1}$ https://www.transformativeworks.org

${ }^{2}$ https://archiveofourown.org
} 
fanart, particularly as it pertains to female sexuality $[11,12]$; others have described how fanart production can creatively empower its artists [88]. Scholars such as Jessica Seymour and Suzanne Scott have analyzed fanart at a somewhat deeper level, considering the artistic intent of fanart and the ways that its outputs can be used to critique its source material $[89,91,92]$. Beyond media studies, art education scholar Marjorie Cohee Manifold has studied fanart creation as a form of informal art education, especially in young and novice artists [20,71, 72]. The generation and dissemination of fanart also bears similarities to creative co-production on other platforms, such as Etsy, DeviantArt, and Dribble [19, 59, 62, 73, 80].

Fanart communities have also shared fanfiction's struggle with censorship, the most relevant of which involves the micro-blogging platform Tumblr. From its founding in 2007, Tumblr thrived as a major hub of fandom activity, often being used in conjunction with $\mathrm{AO} 3$ and other fanfiction websites [45]. However, in late 2018, Tumblr enacted a poorly planned "porn ban" in a misguided attempt to make the site more broadly appealing. Much like the LiveJournal purges before, this content purge not only disproportionately affected queer content creators [49], but also removed Safe For Work (non-porn) fan blogs and support networks for sexual violence [78, 85]. This purge coincided with "The Snappening"-a random mass-deletion of fandom Tumblr blogs, believed to be on the grounds of copyright violation [37]. In the aftermath of this purge, site usage plummeted as fandoms struggled to recover their losses; however, unlike the fanfiction purges that spawned AO3, no better platform has emerged from the current chaos. Alternative platforms such as Twitter and Instagram appear to be equally hostile or otherwise unsuited for displaying fanart, and portfolio sites like DeviantArt do not offer adequate tools for socialization or community-building. As a consequence, fanartists have been largely orphaned. However, given the inertia and resilience we have shown in fandom history, it is neither a surprise nor a coincidence that the last few years have seen a sudden increase in the production of fanart-specific fanzines as a means of staking out new modes of co-production.

\section{METHODS}

In this paper, we report on two related studies with the goal of exploring and describing the complex creative practices and aims of the fanzine community. First, we conducted a set of five exploratory interviews to describe the culture and methods of fanzine co-production. Based on our analysis of these interviews, we conducted a series of digital co-design sessions over a two-month period to gain greater insight into the activist aims of fanzine culture, providing a space for fanzine creators to generatively imagine how they would desire to see their work preserved. These studies were approved by our Institutional Review Board, and all participants were consented prior to their participation. In the sections below, we will provide a description of the primary author's role and background in this community that facilitated this level of engagement, describe our data collection and analysis approach for each study, and detail recruitment procedures used for both studies.

\subsection{Researcher Positionality}

This paper draws heavily from the lived experience of the primary author. At the time of writing, she has been an active member of online transformative fandom for seven years, and has been substantively involved in fanzine communities for five of those years. In that time, she has contributed to over 30 fanzine projects, and successfully ran one project of her own. Her tacit knowledge and networking connections in this space were used to inform the research design and participant recruitment. These connections and prior commitments to fanzine activities and communities marked her as a peer in the co-design sessions, encouraging comfort and reciprocity of engagement in data collection and analysis [101] and trust in dealing with the often sensitive 
nature of fandom interactions and identities [31], while also positioning her as an expert researcher with deep engagement and experience in the study context [75].

\subsection{Study One: Interview Study with Fanzine Moderators}

In order to attain a more complete knowledge of the landscape of fanzine culture, we conducted a series of five semi-structured interviews with fanzine moderators. The goals of these interviews were to: 1) investigate the role of fanzines in contemporary fandom cultures; and 2) gain insight into the creative co-production methods that these moderators utilized.

Moderators, or "mods," act as fanzine project leaders, and take on the role with the highest level of risk and responsibility. From an organizational standpoint, moderators are typically the initiators of a project, and oversee project callouts, contributor recruitment and vetting, content creation, social media presence, sales and finances, publication and manufacturing, and product shipment. Although project teams occasionally divide these responsibilities among multiple moderators, most moderation teams are comprised of three or fewer people. Moderators are often contributors as well, sometimes by design and sometimes by necessity, filling in for contributors who drop from the project unexpectedly. Participants that had previously taken on this moderator role were recruited using mixed sampling methods and the primary researcher's personal network. See Section 3.4 for more details on the sampling approach used for both studies.

3.2.1 Data Collection. We created an interview protocol to encourage open discussion about the moderators' experiences when engaging in fanzine work, building on the first author's personal experiences in creating fanzines in collaborative teams. Interview questions were semi-structured and followed a narrative format that encouraged participants to share personal anecdotes about their experiences organizing, contributing to, and purchasing fanzines [6, 63]. Interviews were 45-90 minutes in duration, and were conducted using the communication freeware program Discord. Audio recordings of these interviews were created and participant identities were anonymized during transcription. Due to the niche and therefore identifiable nature of fanzine projects, anonymization included the redaction of participant names, specific fandoms, project titles, and references to recognizable third parties. Pseudonyms were assigned as necessary.

3.2.2 Data Analysis. The primary author then led multiple iterations of bottom-up thematic analysis $[9,86]$ in the interpretivist qualitative tradition. Our goal in this analysis was to explore and describe the complexity of the fanzine creative production context on its own terms, with a focus on markers of qualitative research quality such as dependability, confirmability, credibility, and transferability $[75,83]$, with strong parallels to modern feminist-inspired inquiry in the CSCW community (e.g., $[3,26,43,101])$. In the first iteration of this analysis, in vivo codes [86] were generated through the systematic sorting of interview quotations from all five interviews. Through discussion, we identified several relevant key themes through a reflexive thematic analysis approach [10]. Early themes included: 1) the processes and pitfalls of fanzine creative co-production; 2) the cultural function of fanzines within the greater fandom space; 3) the appeal of purchasing and collecting fanzines; and 4) the variations on a perceived "norm" for fanzine creation, format, and content. Later iterations of these themes were informed through the writing of the four case studies that we report in Section 4.2. Building on the complexity implicit in each individual fanzine moderator's experience, we constructed four distinct narratives that we report as a multi-case study $[95,109]$. A case study approach allows us to explore the inherent complexity of the moderator experience in depth. Each of the four cases in the study includes a combination of the final themes, reported in Section 4.3, in narrative form: 1) exploring the experiences of a new moderator; 2) moderating a contemporary fanzine with a background in writing fanfiction; 3 ) using the creative 
co-production of a fanzine to revitalize a fandom community; and 4) pushing the boundaries of fanzines as a product.

Based on the multi-case study and cross-case analysis, we were able to construct a clearer understanding of the complexities of fanzine culture and creation within the fandom narrative. From these narratives, we were able to highlight the unique community needs and further examine the existing social infrastructure for addressing some of those needs. These insights formed the foundation for the structure of the co-design workshops, particularly framed by a productive overlap between the visually-focused fanzine culture and the fanfiction-specific Archive of Our Own.

\subsection{Study Two: Virtual Co-Design Sessions with Fanzine Moderators}

Building on the results of the interview study, the goal of this study was to create a space for fanzine moderators to build upon current fandom archival efforts and create the potential for new opportunities for archiving fanzine work. In particular, we desired to create a productive, safe, and empowering environment where fanzine moderators could identify the priorities of their fanzine community and generate new ways to address these needs. We built upon a co-design methodology [87] in order to empower members of the fanzine community to identify and generate outcomes that were resonant with the needs of their community, leveraging their knowledge and expertise in a generative stance.

3.3.1 Data Collection. The primary site for this study was a private chat server hosted by the communication freeware, Discord ${ }^{3}$. The server included multiple chat channels, clustered into roughly three categories: general information on the project, project-specific discussions, and miscellaneous or unrelated discussions. Audio channels were also available as workshops and activities required. Additional tools and sites are discussed later in relation to specific workshops.

Over the course of two months, we conducted a series of four remote co-design workshops on Discord with six participants, with the primary researcher playing the role of both participant and moderator. The remote workshops each utilized a combination of synchronous, asynchronous, and semi-synchronous interactions, and used a modified form of the Asynchronous Remote Communities (ARC) method [70]. Based on the ARC method, we organized our co-design engagement with a clear outline of each workshop, including activities, expected duration, tools, and mediums. However, where the ARC method uses distinct generative (content creation) and recall (reflection) activities, we hybridized our workshops to contain both. Following each workshop, participants were asked to write a short reflection about the activities and overall project progress. The cumulative goals for the workshops were to articulate and prioritize the unique needs of the fanzine community, and generate potential design outcomes to address these needs.

In the first workshop, participants played a simple get-to-know you activity which encouraged them to share their credentials and interests. This workshop did not generate project data, and instead focused on building rapport among designers while familiarizing themselves with the server. Familiarity and trust built in this workshop later became crucial as the designers later grappled with morally-complex design decisions and conversations about controversial and taboo topics.

In the second workshop, we began to explore the problem space by adapting the common User Experience (UX) design method of affinity diagramming [100]. Participants were asked to take a couple of minutes to list as many questions, concerns, and general thoughts that they had concerning a "fanzine archive." Due to participant familiarity and access, Google Slides was used for the sorting and categorization of the collective list items. The results of these were refined into a final list of 10-15 key questions to help better articulate the design space. Additionally, through this

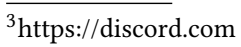


Table 1. Summary of Co-Design Activities

\begin{tabular}{|c|c|c|c|c|c|}
\hline No. & Name & Activity & Duration & Tool & Medium \\
\hline 1 & Introductions & $\begin{array}{l}\text { Participants introduced themselves. } \\
\text { No data was generated. }\end{array}$ & 3 Days & Discord Server & $\begin{array}{l}\text { Text, Photos, } \\
\text { GIFs }\end{array}$ \\
\hline 2 & $\begin{array}{l}\text { Affinity } \\
\text { Diagramming }\end{array}$ & $\begin{array}{l}\text { Participants were asked to brain- } \\
\text { storm ideas related to a fanzine } \\
\text { archive. The brainstorming results } \\
\text { were then compiled and participants } \\
\text { were then asked to sort them into } \\
\text { affinity diagrams. }\end{array}$ & 2 Weeks & $\begin{array}{l}\text { Discord Server, } \\
\text { Google Slides }\end{array}$ & Text, Slides \\
\hline 3 & $\begin{array}{l}\text { Collaborative } \\
\text { Drawing }\end{array}$ & $\begin{array}{l}\text { Participants were asked to collabora- } \\
\text { tively sketch ideas on the same digital } \\
\text { canvas, while conversing over an au- } \\
\text { dio call. }\end{array}$ & $\begin{array}{l}2 \text { Weeks, } \\
\text { Three 2-Hour } \\
\text { Sessions }\end{array}$ & $\begin{array}{l}\text { Discord Server } \\
\text { and Voice, Ag- } \\
\text { gie.io }\end{array}$ & $\begin{array}{lr}\text { Text, } & \text { Au- } \\
\text { dio, } & \text { Digital } \\
\text { Sketches }\end{array}$ \\
\hline 4 & $\begin{array}{l}\text { Telephone } \\
\text { Game }\end{array}$ & $\begin{array}{l}\text { Participants iterated upon a wire- } \\
\text { frame mock-up using a 'telephone } \\
\text { game.' One participant would receive } \\
\text { the design, recreate it, and pass it } \\
\text { along to another participant, and so } \\
\text { on, in a sequential order. Participants } \\
\text { would not be allowed to view other } \\
\text { iterations until the completion of the } \\
\text { activity. }\end{array}$ & 1 Month & $\begin{array}{l}\text { Discord Server, } \\
\text { Misc Art Tools }\end{array}$ & $\begin{array}{l}\text { Text, Digital } \\
\text { and Paper } \\
\text { Sketches }\end{array}$ \\
\hline
\end{tabular}

activity we were able to establish that a shared vocabulary already existed, despite the designers coming from different backgrounds.

In the third workshop, participants joined one of three collaborative drawing sessions to discuss the previously generated questions and articulate fanzine archive designs as low-fidelity prototype sketches. During each session, participants were asked to join a Discord audio call while simultaneously sharing a canvas on collaborative painting application, Aggie.io ${ }^{4}$. Participants were encouraged to use the questions as conversation starters, and to allow the discussion to evolve organically while simultaneously using the digital canvas to visually represent their thoughts. Additionally, due to the "layers" feature available in Aggie.io, participants were able to also interact with the sketches of other participants, adding notes, suggestions, or doodles.

In the final workshop, participants drew from the outcomes of the previous two workshops to design and iterate on the potential digital interface and features of a future fanzine archive. In order to support these interactions, we co-opted a common design method from digital artist communities, the "Telephone Game." The game is adapted from children's game of the same name, wherein children are arranged in a circle and take turns passing a message from one consecutive member to the next in a whisper. Small miscommunications in every iteration cause the original message to evolve over time, often with the end message even vaguely similar to the original. Digital art communities have previously adapted the game into visual form: an artist receives an image and recreates it before sending it to another artist, until there is a chain of unique visual iterations (cf., Figure 1). We recreated this process using two different telephone games. Based on insights gained from previous workshops, the primary researcher created two different interface mock-ups. These mock-ups were then passed from one participant to the next to edit and improve, using whatever tools were at their disposal. When the game had finished, the mock-ups were

\footnotetext{
${ }^{4}$ https://aggie.io/
} 


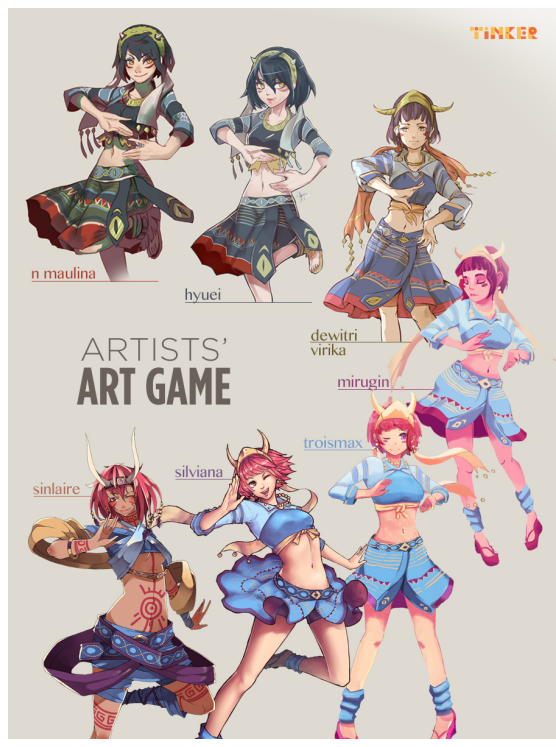

Fig. 1. "Telephone Game" example [76]. Reproduced with the permission of the artist, Ann Maulina.

organized in order and the participants shared their rationale for design changes made between iterations.

3.3.2 Data Analysis. The co-design sessions generated multiple types of data across several different platforms. Discord chat logs and their metadata were downloaded using a third party Discord Chat Exporter application. For the third workshop, which featured synchronous audio discussion and collaborative drawing, we recorded both a screen capture and an audio recording of the group discussion. Afterwards, copies of the canvases were saved as layered psd files and the video recordings were transcribed for analysis. The visual and textual artifacts generated from individual workshop sessions, as well as researcher memos, were all considered in our analysis.

Much of the analysis was conducted in vivo, as was the case with the second workshop, which focused on affinity diagramming. The data generated collectively was subjected to multiple rounds of sorting by members of the design team. The primary researcher, in turn, refined the results with an affinity diagramming exercise of her own, and then submitted the results to the other designers for critique as an explicit form of researcher reflexivity.

The final analysis was focused primarily on the visual artifacts generated in the fourth workshop, and was analyzed in three steps: 1) analysis of changes made between each iteration of the interface design; 2) articulation of key design features and their rationale; 3) comparison to the existing structure of Archive of Our Own. This analysis was substantively informed by the first author's extensive engagement in the fanzine community, alongside regular participation with co-design participants across an extended period of time. Reflexivity was encouraged through regular researcher memos, peer debriefing of design rationale with co-design participants, and data triangulation across the outcomes of multiple workshop activities.

3.3.3 Research Complications. The final third of this project coincided with the outbreak of COVID19 in the United States. Because the project was already entirely remote, the overall research design was unaffected. However, several of the co-designers were met with physical, emotional, or financial changes that limited their ability to participate in a timely fashion. In deference to their health 
and well-being, some of the later activities were extended by multiple weeks, or were modified to accommodate fewer participants or less work.

\subsection{Participants and Recruitment}

Participants were recruited independently for each study, through a mixture of criterion sampling and snowball sampling [7,82]. The criteria for potential participants was as follows: 1) they were a legal adult (age 18+); and 2) they had successfully moderated a fanzine project prior to the interviews. We defined a "successful" fanzine project as one that had broken even, manufactured and distributed all products, and had donated or distributed equally any additional monetary proceeds. Seed contacts were made using the primary author's tacit knowledge of fanzine communities [65]. They were identified and contacted through private fanzine-specific Discord servers, often projects to which the primary author had contributed. Additional participants were identified based on the referrals given by the seed contacts, resulting in a snowball sample.

In order to protect privacy and maintain anonymity in the semi-structured interviews (Section 3.2), no additional demographic details were requested of the participants. However, when considering these interviews in the creation of co-design protocols, we reflexively decided to reconsider the role of anonymity for the second study (Section 3.3). Our reasoning was thus: 1) Participants desired to be acknowledged as advocates and subject matter experts to the academic audience; 2) As designers in their day-to-day lives, denying participants credit for their design work negatively affected their professional lives [13]; and 3) Withholding credit for work contributed free-of-charge is transgressive of a key social norm in fanart culture [41]. Although legal names are omitted from this paper, participants were given the opportunity to designate their own identifier and therefore control the degree to which they are identifiable, as seen in Table 2. Additional care was given to describe the unique skills and experience of each participant in order to highlight the diverse creative backgrounds present in this portion of the project.

Participants were not financially compensated for their time or work, and instead alternative methods were employed to increase reciprocity. Participants in both studies were allowed to view early drafts of results and analysis and give feedback. Co-design participants were given special access to a shared Dropbox folder that contained the otherwise unattainable academic articles used to inform and build this project. After the conclusion of the co-design workshops, participants were given the option of remaining in the project's Discord server to receive updates and give feedback on the project write-up.

Table 2. Study Participants

\begin{tabular}{llll}
\hline Participant & Pronouns & Background & Fanzines Moderated \\
\hline Snowleopardferret & He/Him & $\begin{array}{l}\text { Product designer, illustrator, fanzine moder- } \\
\text { ator (special focus: tarot card projects) }\end{array}$ & \\
\hline Dan & They/Them & $\begin{array}{l}\text { Writer, fanzine moderator (special focus: fan- } \\
\text { fiction) }\end{array}$ & \\
\hline Izu & She/Her & $\begin{array}{l}\text { Animation shot planning supervisor, illustra- } \\
\text { tor, fanzine moderator (special focus: original }\end{array}$ & \\
& & and indie fanzines) & \\
\hline Madin & She/Her & Student, fanzine moderator & 1 \\
\hline pondsizedocean & She/Her* & Teacher, jewelery designer, fanzine modera- & 4 \\
& & tor
\end{tabular}

*pondsizedocean does not have preferred pronouns; for the sake of consistency within the paper, she has approved the exclusive use of she/her pronouns 


\section{RESULTS}

We report the results of the first study in the form of four case studies in Section 4.2. Each case begins with a short introduction of the participant, a brief history of their fandom exposure, and their experience moderating fanzines. Following the introduction, a personal anecdote expands on some facet of fanzine culture, culminating in an enriched understanding of these communities The findings of the co-design are presented in two parts in Section 4.4: first, an examination of the key questions and concerns that were generated by participants for discussion; and second, a comparison of the prototyped archive against the existing framework of Archive of Our Own.

\subsection{Making a Modern Fanzine}

While there is no central authority nor set process for creating fanzines, as is explored throughout the case studies, we were able to establish that the actors in most projects played at least one of three roles: moderator, contributor, and customer. Meanwhile, the interaction of these roles over the span of a fanzine project occured in six distinct phases: interest check, applications, content creation, preorders, production, and fulfillment. We have provided a brief outline of these roles and phases in order to foreground the caes studies in 4.2.

4.1.1 Roles. Within a fanzine, moderators, or mods, are the project leaders and organizers, making the moderator role the most involved of the three. The total number of moderators can vary from a single person to larger teams of 4-6. On projects with multiple moderators, duties are often divvied up for better efficiency. For example, a single project might have three moderators: a social media moderator focused on outreach and promotion, a graphic design moderator tasked with assembling the fanzine for print publication, and a head moderator that both oversees the other moderators and manages the finances and physical production of the fanzine.

By contrast, contributors provide the fanzine's content. Some fanzines delineate these roles further, calling for specific submission types of skill sets: artists who provide illustrations, writers that offer fanfiction, and merchandise artists that can create enamel pins, stickers, or any of the other supplemental materials. Because fanzine projects are reliant on the responsiveness of the contributors, many fanzines also recruit "pinch hitters," which are applicants that are put on a contributor wait-list, and only called on should another contributor drop from the project.

Finally, but just as crucially, customers are the individuals who purchase the fanzine. Due to the niche nature of fanzines, customers are usually treated not as idle consumers, but as active participants in the process. Many customers follow the development of a fanzine project from the first announcements until the orders have been fulfilled, which motivates many project teams to engage with customers through social media: providing status updates on the fanzine's production, publicly responding to questions submitted to them, and running giveaways or mini-contests.

Although these roles appear clearly defined, they are surprisingly fluid. It is possible to, over the course of a single project, inhabit all three roles. Moderators frequently make contributions to their own fanzine projects, subjecting it to the same level of critique and iteration as the other contributors. Meanwhile, while it is the custom for contributors to be compensated for their work with a complementary physical copy of the fanzine, as well as all the supplemental merchandise, many contributors purchase extra copies, sometimes for their personal collection or portfolio, sometimes as gifts, and sometimes as personal stock at an convention booth.

4.1.2 Phases. In all, a fanzine project can take anywhere from three months to a year and a half to run to completion, depending on a variety of factors, such as extenuating life circumstances for moderators or contributors, the current demand and relevancy of a project, or the total number of contributors. However, as stated previously, despite the variations in structure and timeline, there 
are usually six distinct phases in a fanzine project: the interest check, applications, content creation, preorders, production, and fulfillment.

The interest check refers to the early period of research conducted by moderators in order to gauge the activity and interest of both potential contributors and customers. This check relies heavily on social media, and uses a variety of methods, including: announcement posts, polls, and surveys. With sufficient engagement, the applications phase is initiated. The applications phase marks the team formation period, and usually involves interested contributors submitting portfolios to the moderator team for consideration. Moderators then select contributors from the available pool of applicants, and proceed to the next phase. The content creation period is the 3-6 month period wherein contributors develop their pieces. Often, contributors are invited to a shared space, such as a Discord server, where they are encouraged to interact with moderators, seek help in their own content creation, and offer critique to those seeking similar aid. To help facilitate this and maintain a schedule, moderators often utilize a series of "check-ins" to ensure that the final deadline is met. Fanzine preorders follow the content creation period, and are usually heralded by a social media campaign to raise awareness and customer engagement. Individual contributors lend a hand by posting previews and teasers of their works with their own networks and followers. After preorders close, the fanzine project immediately launches into the production phase. Externally, this phase is both the longest and least exciting phase of the project, as much of the work and decision making falls entirely to the moderator team. Fanzines are formatted for publication, merchandise is proofed for production, while moderators coordinate and negotiate the specifics of manufacturing Following the long, stressful production period, the disparate pieces are gathered together in a single location for the fulfillment phase. Bundles of goods are then assembled, packaged, and shipped across the world. This process requires careful navigation of shipping costs and tax laws, tracking packages, and addressing customer concerns over lost packages and damaged goods. A project is normally only considered complete when all the customer orders have been fulfilled, and all contributors have received their complimentary bundles.

\subsection{Interview Case Studies}

4.2.1 Finn: A New Moderator's Journey. Finn had spent the last eight years on the cosplay scene, building costumes and performing as fictional characters at comic conventions. Although he has only recently become aware of fanzines, he has since actively pursued roles as as a contributor and moderator. At the time of the interview, his most recent project marked the first time he'd acted as a fanzine project's head moderator.

How To Run a Fanzine (By Knowing How Not To): Finn's first fanzine project didn't end well. To be fair, it hadn't started normally either. Rather than applying in the early stages of the fanzine, he had been contacted and invited well after the launch. Somehow, the initial participant count had come up short and the organizers had reached out to Finn on referral. They were looking specifically for cosplay photos, and luckily Finn's schedule already lined up. He already had an appropriate cosplay on hand for an upcoming convention, so it was simply a matter of arranging the photo shoot. Things went smoothly on his end, but shortly after the project went south.

"The head moderator and the person who was going to ship all the zines actually jumped ship and left us all alone and deleted all of her social media, all of everything, and just left a message on her DeviantArt saying she was leaving forever for no reason. And just left."

Although the remaining contributors made a valiant effort to complete the project, without a head moderator things sank quickly. Thankfully the project had still been early in development, which meant that no money had been taken on preorders. With no financial obligation the contributors 
decided that the safest route was letting the project die a natural death. Finn moved on, but he never forgot the dramatic dissolution of his first fanzine project. As he continued to engage in the fanzine community, he began to notice a trend in projects that went the way of his first: the moderators.

"I can name drop a few failed ones... Just because of moderators who lied about being 18-20 years old and they're actually $14-16 \ldots$ teenagers, people who think that school club experience is enough to be a zine moderator. Organizing events is a lot different than handling money to who knows how many people are going to buy it, you know?" (Finn)

Age wasn't the only factor. Finn learned to become deeply suspicious of moderators that obscured their identity, or otherwise attempted to dodge accountability. This was often marked by a lack of transparency between moderators and their participants and customers, with long gaps in communication, unanswered emails, and dormant social media accounts. The worst case scenarios involved moderators vanishing after the preorder period, stealing the money from their customers and failing to provide their contributors with any form of compensation.

By the time Finn launched his own project, he felt well equipped to avoid the pitfalls of his predecessors. One of his first actions was bringing another moderator, Mint, onto the project. Mint was a seasoned fanzine moderator and a long-time friend. On paper, she was the social media manager, but she also acted unofficially as Finn's mentor. The rest of the project was structured with similar consideration for professionalism and transparency. Additional moderators were added to split the work load and increase accountability, each one carefully vetted prior to their inclusion. They established accounts on Twitter and Tumblr, working to build awareness of the project and to keep interested parties informed. By the time contributor applications opened, Finn felt he had build a team that could be relied on.

For the majority of the project, things went smoothly. Contributors were equally well vetted, and then democratically selected by the moderator team. They created and maintained a private Discord dedicated to the project, where contributors could easily contact moderators with questions and concerns. Clear communication and enforcement of rules led to peaceful interactions between participants in the server, who were encouraged to interact and give constructive feedback. A careful budget and successful preorder period predicted that the project would break even. After receiving the funds from the preorders, Finn began making purchases. Merchandise came first, with the manufacturers pre-selected based on research and recommendations. The physical fanzine came last; however, when he went to make the purchase, he was surprised to find insufficient funding. Somebody had stolen $\$ 400$ of their funding, and after several panicked phone calls, Finn was informed that there was nothing the bank nor the third-party app responsible could do about it. Redoing the calculations presented a grim new reality: they were short on funding for the printing, and had nothing left over for shipping. However, Finn felt he was both morally and legally obligated to see this project through to the end, and decided to continue printing, aware that he would be paying any further costs out of pocket.

Devastated by the theft and frustrated with management and miscommunication issues with his printer, Finn was terrified of having to face his contributors. He worried that the delays would make his explanations sound like excuses, and that the contributors might think he had secretly taken the funds. However, here his preparation and diligence saved him once again: at this point in the project, his carefully vetted participants had seen his dedication and transparency, and were both sympathetic and patient as the project dragged on. Finally, after weeks of back-and-forth between Finn's team and the printers, the fanzines arrived. And to his great relief, they were beautiful-at 
least the quality of the printers hadn't disappointed him. He still had to ship everything using out-of-pocket funds, but at least he could finally begin fulfilling orders.

There was one last surprise left in this project. Rightfully frustrated, one of the moderators left a negative review about their printing problems, mostly as a warning for future fanzine moderators To their surprise, a couple days later they were contacted by the owner of the printing company, who asked for further details about their negative experience. After reviewing the emails, the owner offered them a deal: they would refund Finn $50 \%$ of the print costs, if Finn's team would update the review to acknowledge that their grievances had been professionally addressed. Although the refund did not make up for the amount lost in the theft, it did relieve some of the financial burden of paying for shipping out-of-pocket. In the end, Finn's careful preparation hadn't been enough to avoid every risk of fanzine production. His integrity and diligence, however, helped him minimize the damage and keep the confidence of his contributors until all his obligations had been fulfilled

4.2.2 Ray: The Intersection of Fanart and Fanfiction. Ray has been a member of fandom since middle school, but they've been at least peripherally aware of fandom for much longer. They experienced first hand how the internet changes the fandom experience from small, intimate groups limited by geographical areas, into a massive global network. Now an adult, Ray has successfully moderated a fanzine project, and continues to contribute fanfiction to a variety of fandoms.

Networking with Artists, as a Writer: Shipping has long been a major draw of fandoms. "Ships"-short for relationships-are typically the non-canon romantic, and often queer pairing of two characters. Within any given fandom, there is normally a handful of common and popular ships, which are usually supported by a relative deluge of fan creations, both in the form of art and writing. However, there are also the uncommon ships, sometimes called "rarepairs," which lacked fandom support and fan-made content. This was what Ray discovered upon entry to the new fandom forming around newly airing anime, ShounenOne $e^{5}$.

Fan content of their favorite ship from the show, a queer rarepair called EKR, was severely lacking. According to conventional fandom wisdom, when faced with a rarepair you either resign yourself to the very limited amount of content (usually a handful of fanfiction works and the occasional fanart, usually created by one of the same five fans and quickly buried under content for more popular ships)... or you make new content yourself. Ray opted for the second route: "It was something I wanted to do cause I like EKR and at the time there wasn't a lot of merchandise of both of the characters together in the same piece of merchandise and I wanted it; so somebody's got to do it."

There was a small problem, though. In order to increase the popularity of a rarepair, you need buy-in from the rest of the fandom, especially the artists. As a fanfiction writer, Ray initially lacked the connections with the fanart community. Rather than a barrier, though, they considered this an opportunity to connect to the talented artists across this new fandom, and the best way to go about it was through a fanzine.

Research came first. Ray knew fandom; they knew fanzines, and their early history included efforts as an underground back channel for sharing fanfiction. And they knew that fanzines had changed significantly in their latest iteration. As they sought out advice and references on fanzine production, Ray came to a couple of key decisions: first, they would be the only moderator on their debut project, and second, they would set aside a financial safety net in case the project failed to break even. This decision was made largely to reduce the overall risk, but just because they were going solo didn't mean they were doing this alone. One of the earliest parts of the process involved gauging whether there was even an interest in their fanzine. This "interest check" took the form of a simple Twitter poll, but it required help from some of their few fandom contacts for it to gain

\footnotetext{
${ }^{5}$ Series title has been anonymized
} 
visibility in the young fandom. As a result, the poll saw decent circulation among interested parties, enough for Ray to green light the project.

To their surprise and excitement, Ray never needed to draw from their emergency funds. ShounenOne's first season had run its course, and in the absence of new official content, fans were frenzied for fan creations to help fill the void. When applications for their project open, Ray was taken by surprise by the sheer number of applicants. Not all were qualified, of course, but it still left Ray scrambling for weeks performing background checks, contacting individual artists, and setting up clear expectations and deadlines for their new contributors. Over the next few months, Ray continued to work tirelessly to collect and compile illustrations and establish supply chains for printing and production. But the fandom fervor held steady, and preorders were received with such aplomb that the project not only broke even, but made a profit.

"I would consider it a success because there was more interest in it for applicants than I had anticipated... There were more preorders than I had anticipated and in the end, after a year I sold out all of the copies. So I don't have any excess copies still lingering after like a whole year of having them for sale." (Ray)

The project's success extended beyond the financial. After all, Ray had successfully rallied the artists of a new fandom to create content in celebration of a ship that had previously been a rarepair. It boosted Ray's confidence in their own abilities, prompting them to informally tutor a number of other prospective fanzine moderators, and even host a panel on the topic at a local comic convention. Most importantly, though, Ray had learned not only how to successfully navigate fandom spaces and network for themself, but also how to create networks for others too.

"Artists tend to be intimidated by each other, and I've learned that artists are not intimidating people... They're people just like you are. So in that way, it's helped me grow, not just networking for myself, but to help other people network with one another." (Ray)

4.2.3 Nia: The Cultural Role of Fanzines. Nia regularly cycles through roles in creative spaces: student, teacher, illustrator, animator, product designer, and so on. She splits her time between teaching art classes and managing her web-based business. When given the opportunity, she sells her wares from comic convention artist alleys, where her preference for traditional art mediums set her style apart from many contemporaries. To date, she has contributed to eight fanzines, and also acted as moderator on three of them.

Creating a Fandom Revival: Fandoms often run in cycles related to the production and release of new official materials. With the release of a new season of a TV show or the next book in a series comes new content for fans with which to engage. In between official updates, however, fan devotion often slowly tapers off until the fandom is considered "dead." Most of the time, though, "hibernating" is a better descriptor.

It was no secret that the ShounenClassic fandom was among the "dead" fandoms. The series was well loved, but suffered from an erratic update schedule that spanned some 25 years, making it difficult to maintain the fandom. Attempts on the part of IP holders to revive the series only put more nails in the coffin with the release of a hilariously bad TV series remake. None of this dissuaded Nia from stocking her artist booth with her ShounenClassic fanart prints, even if she didn't expect it to sell much compared to her other wares. To her delight, however, she was not alone in her resolve and found a small handful of other artists at the convention doing the same. In spare moments over the next few days, they bonded over ShounenClassic and relished the growing realization that there might be more life left in the fandom than they had previously believed. By the time the convention had ended, Nia and another artist, Swirly, decided that it was time to do 
something about it. Neither of them had the resources of clout to orchestrate a total fandom revival; however, they set their sights on a more temporary revival, facilitated through a fanzine project.

Although neither had organized a project like this before, they already had a leg up. The network they'd built at the convention supplied them with a guaranteed pool of established artists, whose individual networks could be used to recruit their remaining contributors. In addition to generating some 80 applications through an open call for applicants, Nia and Swirly also issued private invitations to a number of established artists that they knew had previously participated in the ShounenClassic fandom. Once they had picked their 35 contributors, they launched into the next phase of the project.

Nia and Swirly's partnership brought a degree of stability to the project. Regular check-ins and open communication allowed them to delegate tasks, and establish a series of milestones to help keep the project unified and moving forward. They were also able to leverage the unique skills or networks either had, such as calling on Swirly's personal connection to a local printer to produce the physical copies of the fanzine. The co-production of the project also delivered on their desire for a fandom revitalization. Although the project predated the common use of Discord channels, the fanzine visually connected younger fans to the veterans. This, in turn, helped energize other members of the fandom whose enthusiasm extended into preorders, thus pushing the project to financial success. Although they knew that the excitement couldn't last forever, the fanzine did what it was designed to do: rebuild the fandom network long enough to create a tangible way to reflect on it all: the fandom, the fanzine, and the friends made along the way.

"The entire concept of zines, every part of it-participating, buying, organizing-all comes from this kind of desire to have something to commemorate that time in your life and the time within the fandom. [...] It's almost like how people make those scrapbooks of pictures and stuff, to have memories. It's literally the same, but like with fanart: 'Let's all do this one piece and put it in a book and then put the book out and we'll all have this to remember this time by.... I don't think I ever thought of this that way before we started participating in zines, but now that I have a solid shelf with a whole bunch of them that I've participated in, it's just, I dunno. I look at it and it makes me happy." (Nia)

4.2.4 Lio: the Benefits of Fanzines. Fandom has always important in Lio's life. His mother had been a member of the original Star Trek fandom, so he had grown up familiar with fanzines and mailing lists. As an adult he went on to participate in an array of fandoms as an illustrator, product designer, and cosplayer. When, in the past few years, fanzines began circulating again he was quick to jump on board, first as a customer and then as a moderator. In particular, he draws from his special knowledge of the occult to help organize tarot card projects.

Variations on a Zine: Tarot card readings are a centuries-old divination practice that relies on a symbolic card deck to provide insight into the past, present, and future. A complete tarot deck consists of 78 symbolically unique cards split into a Major and Minor Arcana. Fandom tarot projects have gained in popularity over the years. On the surface they share a similar infrastructure to other types of fanzine projects: moderators oversee contributing artists and organize the production of books and merchandise. However, tarot projects introduce several layers of complexity.

First, despite the use of tarot in popular media, to many tarot cards are a religious artifact with great spiritual significance. Creating a proper deck knowledge and respect to ensure that the illustration on each card aligns with its symbolic meaning. Second, tarot card projects are big. Where most fanzines usually cap at around 30-40 contributors, tarot card projects require around 70-80. This not only increases the organizational burden on moderators, but also increases the break-even point in order to accommodate the large number of complimentary contributor copies. 
Finally, high-quality tarot decks requires specialized production, which increases financial burden by increasing the minimum number of units a manufacturer requires for production. In comparison to fanzines, tarot projects are significantly more work and higher risk to moderators.

Despite knowing all this, Lio didn't ease himself into fandom tarot card projects. Instead, he saw an interest check for one of his fandoms and decided to jump right into the deep end.

"And I knew approximately how much work is zine was, and I knew how much more work a full scale Tarot deck was going to be. So I contacted [the head moderator, Casey] and offered my services as somebody who knows the format of tarot projects and is really good at... um, I've always had a bit of a passion for translating fandom stuff into witchy stuff. It's a personal passion of mine. And so I offered to assist in that project and Casey took me on as an assistant. And from there I've run my own fanzine at least once and helped Casey with several." (Lio)

Part of managing large projects was learning how to shepherd artists. According to Lio, the internal dynamics shift from project to project, often in reflection of their fandoms. For instance, he noted how one of his projects had been based on a popular Battle Royale-style video game. Their project had brought in a lot of extremely talented artists, but many of them struggled to take direction on their pieces, preferring to "bull rush ahead no matter what anyone else is saying." These are behaviors useful in competitive gameplay, but problematic in collaborative creative work By contrast, his most recent project was based on a more balanced, community-centered video game. Although the artists were of similar calibre to the other project, they did not exhibit the same aggressive, individualistic behavior.

Overarching fandom trends aside, these sorts of complex interactions were also present in individual interactions as well. Lio keeps a personal blocklist, which he describes as "artists that I've personally worked with and never wish to work with... It's a very short list because it's reserved almost entirely for people who have fucked us over and really pissed us off." By contrast, Lio also keeps an MVP list of artists who have consistently met project deadlines with quality artwork. In fact, Lio and Casey's tarot projects regularly attract industry artists, who contribute professional illustrations for little or no monetary compensation.

"I commissioned one of my artists too... I've had them do two [tarot] cards, and I'm asking them for a [commission] piece that's approximately the amount of work I asked them to put into a [tarot] card and I put $\$ 450$ down on that commission and that was at a discount rate." (Lio)

Which is not to say that artists aren't compensated. Contributors receive a complimentary tarot deck and book, and where resources allow, merchandise as well. To help offset costs further, contributors are allowed to purchase extra copies at production price, which they can turn around and sell for profit at a comic convention artist alley booth.

"A lot of what I've seen them take away is a sense of pride in their completed pieces and having been a part of something exclusive, exciting and explosive. But also, the community actually around producing the zine itself has been a big benefit to, I would assume, to artists I've worked with because there's an odd sort of ephemeral waterhole kind of culture that springs up in the Discord servers...these are people who may not have ever communicated, sought each other out in a broader public space, but now they're all working together and they're providing constructive criticism on each other's pieces. They're discussing the fandom in a relatively closed and safe space." (Lio) 
Finally, Lio described how artists share some of the benefits of a fanzine with the customers who purchase them: "They provide me a permanent hard copy of something that would otherwise have been ephemeral. It's like a snapshot. This is what the fandom was up to. This is what I was interested in at the time."

"Also, there's exclusivity... I consider myself a toy collector, but I acknowledge that a lot of what toy collecting is, is essentially like a big dick contest about who has the most money. But that's the thing about zines, is it's not a contest about who has the most money. It was about having been there to get it and it provides a different sort of thing for a collector, emotionally." (Lio)

Despite the challenges of navigating and coordinating such large groups of artists, and all the drama that comes with it, fanzines have played an important part of Lio's life. If all goes well, he fully expects to continue working on fanzines and Tarot projects, and continuing to explore their potential variations.

\subsection{Cross Case Summary and Themes}

The case studies serve to highlight the dynamic complexity of multiple elements in these fanzine engagements. Notably, most of the fanzine projects we heard about were grassroots and relatively decentralized, making use of social media, Discord servers, and fan conventions. However, while some technological infrastructure was required, much of the organizational labor took on a more personal tone, with a requirement to consider both the logistical concerns relating to production of physical goods and the ability to manage a wide range of collaborators in the production of creative material. Beyond illustrating the social and technological processes by which fanzine projects are organized, the case studies also brought to light a series of themes that are expanded upon in the following subsections.

4.3.1 The Identity of Fanzines. At a cursory glance the obvious cosmetic differences between traditional fanzines and their most current iteration gives the impression that the identity of fanzines-that is, by whom and for whom they are made, and for what reason-has fundamentally shifted in the past couple decades. As discussed previously, many of the original fanzines were simply constructed, sometimes little more than xerox copy and staples, which contrasts sharply against the refined, art-centric fanzines of the modern day. However, closer examination of current fanzine productions implies that the divergence may not be as severe as obvious aesthetic differences might imply.

Across the case studies, fanzine moderators displayed a varied knowledge of the historical roots of the fanzine movement, such and Ray and Lio receiving exposure to through fannish parents. However, regardless of whether the moderators had this direct connection to the past, their fanzines continued to contain content created by fans for the consumption and enjoyment of other fansregardless of the continued dubious legality of their production. Perhaps the most obvious echoes were illustrated by Ray, whose fanzine project not only focused on a non-canon romantic ship, but one that was explicitly queer. Nia's case, wherein she used her fanzine project to facilitate new connections within her fandom, exhibits how fanzines continue to act as important channels for networking and sharing ideas. In general, one of the core motivations for fanzines-collaboration and connection between fans separated by geographical distance-has merely expanded to a global scale, with the internet enabling applications from across the planet. Although they may no longer look like the "scrappy" underground publications of their early years, fanzines' most current incarnation continues to inhabit the same spirit and identity as its predecessors. 
4.3.2 Benefits of Fanzines. The case studies presented a wide array of benefits to participating in fanzine projects, particularly for the content contributors. However, very few of these benefits come in the form of direct compensation, especially because many fanzine projects are built around charity initiatives, acting as both opportunities for community engagement in activism, as well as as an attempt to continue claiming legal "fair use." Lio's story clarified this further, describing at length how splitting profits among so many contributors usually led to a relatively meager payout. Even when factoring in the value of the complimentary contributor copies of materials produced in the project-a standard practice also mentioned by both Ray and Finn-the direct compensation for each contributor does not reflect industry standards.

Several of the moderators offered insight into these non-monetary benefits: Ray, for instance, cited the opportunity to create something that would and could not ever exist outside of fandom, particularly in providing queer content. Lio offered up the community built around fanzines as one of the driving motives, providing a safe and supportive, albeit temporary environment to network and learn from other artists, an attitude which is further reinforced in Nia's narrative of community formation. Overall, the participants felt that the lack of direct compensation illustrated in their stories was not the result of an unfair or broken system, but rather as another example of fandom's gift economy.

4.3.3 Fanzines as Products. Although fanzines fit well within fandom's gift economy, as we have just discussed, it is also important to examine them as products. Despite being physically produced, sold, and subjected to taxation, fanzines remain of dubious legality. Finn's story explored how this strange, gray legality robs both fanzine moderators of a safety net and fanzine contributors and customers of the ability to hold bad moderators accountable. However, throughout the case studies, we also saw how the project moderators held themselves to high levels of professionalism, with Finn and Lio offering insights into the ways that good moderation teams are formed and held accountable internally.

This dedication to creating a high-quality product was also reflected in the careful vetting and selection of contributors using a variety of methods, such as: conducting basic background checks (Ray), openly discussing and voting (Finn), extending personal invitations to specific contributors (Nia), and keeping curated lists of recurring applicants (Lio). As a result, when applying the high quality content created by contributors to similarly high quality production and materials, the result is fanzines and merchandise that rivals or surpasses the quality of "official" merchandise.

This is because official merchandise is usually created with the intention of rapid mass production, with quality that varies from average to bad. If higher quality official merchandise is created, it is usually priced for a high profit margin, marking them as luxury items and limiting their accessibility to the majority of fans. Beyond the material quality, official merchandise is usually restricted to a handful of corporate-approved publicity images, which are simply remixed into different compositions or mediums. By contrast, fanzines offer not only quality, but a variety of styles and compositions. Since fanzines and their merchandise are not bound by corporate rules or even the IP canon, fanzines can provide quality, supplemental materials that will never be provided through official channels, particularly concerning queer or adult readings of canon properties. As such, while fanzines are technically not legal, they exist more as a niche product, readily accessible to fandom members and providing a product that does not directly compete with its official counterparts.

4.3.4 Fanzines as Archives. The final theme we identified through the interviews and case studies is the role that modern fanzines play as a distributed form of fandom archival work. The last few years have seen a series of social media policy changes that have severely battered online fandom communities, in ways that have disproportionately affected marginalized groups who use transformative work to explore queer identity and adult themes. The destruction of fandom 
infrastructure has been an unfortunately common occurrence since the beginning, but while the modern era offers greater protection and archival tools, fanart and other visual mediums remain frighteningly vulnerable to these content purges. When entire content creators, blogs, or galleries can vanish overnight, fanzines offer a physical record of their existence.

In the case studies, Nia and Lio spoke specifically on this matter. While acknowledging the beauty of the art recorded in fanzines, she frames them more emotionally as "scrapbooks," emphasizing that for the fanzine contributors, the process and memories captured in the fanzine were equal weight to the final product. Lio echoed a similar point in his interview, but instead focused on the benefit to fanzine customers. In his framing, fanzines were "collectibles," rather than scrapbooks: tangible proof that you had existed as part of a community at a specific moment in time. Both framings, however, underline the continued fragility of fandom, and the fight not only to exist, but to for that existence to be remembered and acknowledged-a plight reflective of the marginalized communities that occupy these transformative spaces.

4.3.5 Summary. These interviews and the resulting case studies were crucial in informing our understanding of the structure of fanzine projects and the ways that technology has been implemented to produce them. Despite many of the surface differences between current fanzines and their predecessors, these interviews helped clarify that the spirit of collaboration and resistance to existing oppressive structures in the pursuit of creative expression is alive and well within the current culture. However, when investigating the way that fanzines have shifted away from fanfiction towards fanart, we realized that the current fanzine revival was motivated in no small part by the lack of archival infrastructure for fanartists. These insights became the foundation for our co-design work.

\subsection{Co-Design Activities}

Building on our understanding of creative practices from our interviews, the set of co-design activities that we engaged participants in over a two month period generated large amounts of data in a variety of formats: drawings, audio discussions, and chat logs to name a few. However, although these workshops guided objectives, goals, and timelines, participant discussions outside of the structured activities provided additional depth to our study. We were able to tap into these conversations by leveraging the Discord server as a primary point of interaction for our study. All participants were familiar with Discord server etiquette prior to beginning the co-design Throughout the project, on-topic channels-such as those focused on specific workshop interactions and reflections-were used only strictly for their intended purpose. Although the dialogue between participants was never formal, it rarely strayed from the objective. By contrast, the off-topic channels were filled with long, rambling discussions, some truly off-topic but the vast majority still pertaining in some part to the project.

An emergent finding from the affinity diagramming in the second workshop was that, despite coming from different fandoms and backgrounds, the participants shared a technical jargon. One phrase in particular resonated with the participants: "Be gay, do crimes." This motto is common in many fanart communities, both as an acknowledgement of the inherent queerness of fandom and the fan works they produce, as well as continuous reminder to resist and push back against would-be oppressors. For fanzine moderators, many of whom had experienced copyright strikes for selling their fanart or, in one extreme case, the shutdown of a massive fanzine charity project, the actual "doing of crimes" was simply a way of life. The solidarity between fanzine moderators who stubbornly, almost spitefully continue to organize and publish despite the looming legal threats further cemented the bond between participants. 
As rapport grew between them, participants could be relied upon to initiate conversations without the prompting of the lead researcher. Participants began to discuss fanzine moderation in greater depth, swapping personal anecdotes, sharing trade secrets, and airing personal grievances. One particularly memorable discussion involved snowleopardferret, Izu, and Madin commiserating over the difficulties of organizing and managing dozens of artists. They accomplished this by recounting specific ways that their announcements or instructions might be ignored or otherwise overlooked, no matter how much care was put into the wording. Between examples, they offered additional description with colorful metaphors, such as:

Snowleopardferret: I'm like a golden retriever in a tennis ball court [...] Artists and tennis balls: both bouncy and exciting and cannot read

Izu: I'm a shepard leading a flock where my sheep just fuckin run off cliffs

Snowleopardferret: I have 100 cats and one spray bottle and a can of tuna... a third of the cats hate tuna for some reason

Eventually, these conversations began to meld with the overarching project. Between workshops, participants used the off-topic channels to review and reflect on the progress that they had made. For instance, the initial list of questions created in the second workshop was informally iterated upon multiple times in the off-topic discussion channels before the third workshop had even begun. During later workshops, participants would refer back to chat logs or revisit old questions. As a result, the project was not a set of four distinct workshops so much as it was a messy and iterative cycle of discussion and debate. We present the results of the triangulation of the data gathered from workshops and informal discussions as follows: First, we examine the key questions that the participants identified, articulated, and iterated upon as they completed the four workshops; Second, we compare the archive designed by participants with Archive of Our Own's existing model.

4.4.1 Key Questions. Over the course of the co-design, the goals and priorities of participants shifted. At first, participants showed some interest in designing the visual interface of the fanzine archive (Figure 2; however, as we delved deeper into the problem, the interface became secondary to questions of best practices, social norms, and legality. Eventually, we distilled these questions into a set of key categories, which we then expand upon together in greater detail.

Q1: How should we build the fanzine archive's framework? At the beginning of the project, we tried not to encourage participants towards any specific preexisting archival model. However, as participants discussed and conducted personal research, they quickly came to the conclusion that creating an archive from scratch was both outside of their ability and redundant. Rather than envisioning a totally new archive, they instead reframed the project as the creation of an extension to Archive of Our Own's existing framework. While this immediately answered many technical questions, such as cataloguing and tagging, it also helped to frame remaining questions, as we will discuss here shortly.

Q2: What features should be added to support fanzines? In acknowledgement of AO3's limitations in storing and displaying visual artifacts, participants gravitated towards using PDFs as the submission format. As a result, a PDF viewer was identified as the most important feature to be added to the existing archival structure. Accessibility features, such as alt text, were also included in this discussion. Additional features discussed included a gallery of non-fanzine merchandise (such as keychains, postcards, lanyards, enamel pins, etc.), as well as a wiki-style "history" section.

Q3: How do we keep the archive legal? As mentioned previously, "Be Gay, Do Crimes" is the general sentiment of many fanartists; however, this is not a blanket endorsement that gives fanartists carte blanche to break any law or rule they wish. Rather, it is a statement of resistance against powerful institutions, particularly pointed towards attempts to control and commodify creativity and culture. Our participants acknowledged AO3 as an ally in this resistance, and as 


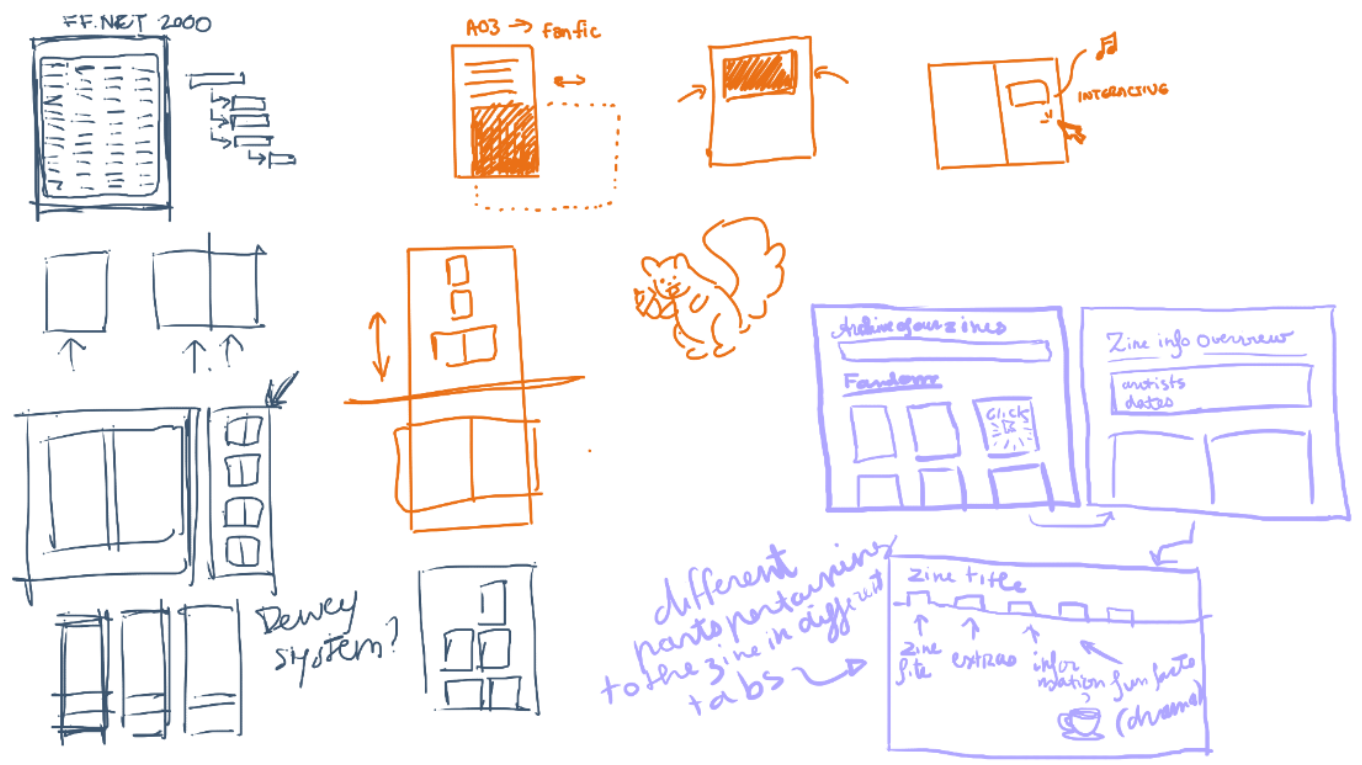

Fig. 2. Early digital sketches as co-design participants explored archival opportunities for fanzines.

they attempted to graft fanzines onto the existing framework, they realized that this allyship also meant that fanzine work needed to adhere to terms of service that legally protect the archive and its artifacts.

The first concern was the fact that, in order to be protected under fair use, AO3 is necessarily a non-profit organization. By contrast, most fanzines make some form of profit, even if that profit is minimal, incidental, or donated to charity. Attempting to archive a fanzine currently for sale elsewhere would also hurt the ongoing project. The workaround that the participants decided on was that only "closed" projects would be admitted to the archive. If users could provide proof that a fanzine was still for sale on another site, that would constitute grounds to have it removed.

The second source of legal concern came in discussions of adult content. Participants were not worried about AO3's continued support of explicit content, so much as they were aware that visual porn was often perceived differently than textual porn-specifically in relation to cartoon child pornography. The issue of adult content is problematic, since it involves both explicit scenes of characters that may be underage, and that some of these scenes may be drawn by young fanartists that may be close to these characters in age. Additionally, pseudonymity in these communities could result in moderators or or other members lying about their age, resulting in additional issues relating to access to explicit content. After serious thought and consideration, participants decided that they would have to consult with legal experts to determine how to handle this situation due to its many complex dimensions. For the remainder of the project, they considered this an unresolved issue.

Q4: How and where should we give individuals credit? One of the key differences between $\mathrm{AO} 3$ and the fanzine archive, participants decided, was that the individual submitting a fanzine did not necessarily have to have been a moderator or contributor on the project. The rationale provided by participants was that it was incorrect for one person, even a moderator, to claim that they had authored a fanzine. Individuals who submitted fanzines would be credited as donors rather than authors. 
The participants also noted AO3's "orphan" function may be of use, allowing individuals to unlink submitted fanzines from their accounts, allowing the fanzines to remain in the archive even if the original donor ceased participation. In that same vein, it was decided that multiple submissions of the same fanzine would be considered a feature rather than a flaw, as it reduced the risk of losing a fanzine altogether, should a donor choose to delete their fanzine submissions altogether.

This in turn led to discussion of how individual fanzine contributors could be credited. Several problems immediately came to light. In fandom, usernames and handles were often fluid, meaning that the listed credits in the fanzine would sometimes lead to a dead end, with no way to contact the creator of a specific illustration. In addition to the level of work and the potential for fraud, there would be cases where a fanzine contributor might actually be putting distance between themselves and a specific fandom, for any number of reasons. Eventually, the solution they settled on was submitting the credit handles as tags in the archive system, rather than linking them directly to some outgoing portfolio or social media account.

Q5: What is a fanzine? Participants displayed openness to a fluid definition of 'fanzine.' Going into the project, all the participants had moderated or at least encountered fanzines that already pushed the mold: tarot cards and recipes were judged as worthy fanzine content just as much as artwork and writing. In fact, participants were open to using the archive for non-fan zines, drawing a comparison to how some have begun to use $\mathrm{AO} 3$ to post original writings. It was also pointed out that if the definition of fanzine were expanded to include doujinshii (Japanese fan comics), a fanzine archive would be an excellent place to encourage and document their translations. On the whole, participants took the attitude of excitedly identifying people who could be brought in, rather than targeting those they wanted to be left out.

4.4.2 Framework Comparison. At the very beginning of the co-design, some participants drew on their graphic design or illustrative backgrounds, floating questions about the purely aesthetic aspects of the yet-to-be-proposed fanzine archive: interface design, colors, logos, etc. After the participants began to use $\mathrm{AO} 3$, the visual elements became consistently less central as the project progressed. Instead, participants focused on the core felt needs of their community, identifying what elements were required in order to accurately preserve their fannish history.

Tagging and Technical Infrastructure. After weeks discussing these core elements, participants were asked to return again to their visual roots in the final workshop, "The Telephone Game," seen in Figure 3. This time, though, they barely considered the aesthetic elements of the archive. Instead they grappled with translating the needed elements, identified collectively across the previous workshops, into practical features. Moreover, these practical features, which were fundamentally designed to support a visual medium, needed to also translate to AO3's text-based platform. Through the iterative designs, it became clear that if only PDFs of fanzines were archived, only one additional feature was required: a PDF manager. Participants recommended a few sub-features, such as allowing for the entry of notes or alt text, or automatic watermarking to prevent fanzine theft and illegal resale. Beyond the PDF manager, there were a handful of smaller adjustments, but these were merely additional metadata that could be appended to the AO3's existing functions: project start and end dates, donation records and amounts, and so on. Beyond that, the group felt that the existing AO3 tagging system could support fanzine archival work at a very basic level. However, while this incremental approach might be sufficient for some very basic archival work, it fundamentally would not service the community for which it is intended.

Authorship and Permissions. The difference between the needs of the fanzine and fanfiction communities become starkly apparent in an examination of how AO3 handles authorship. Currently, 

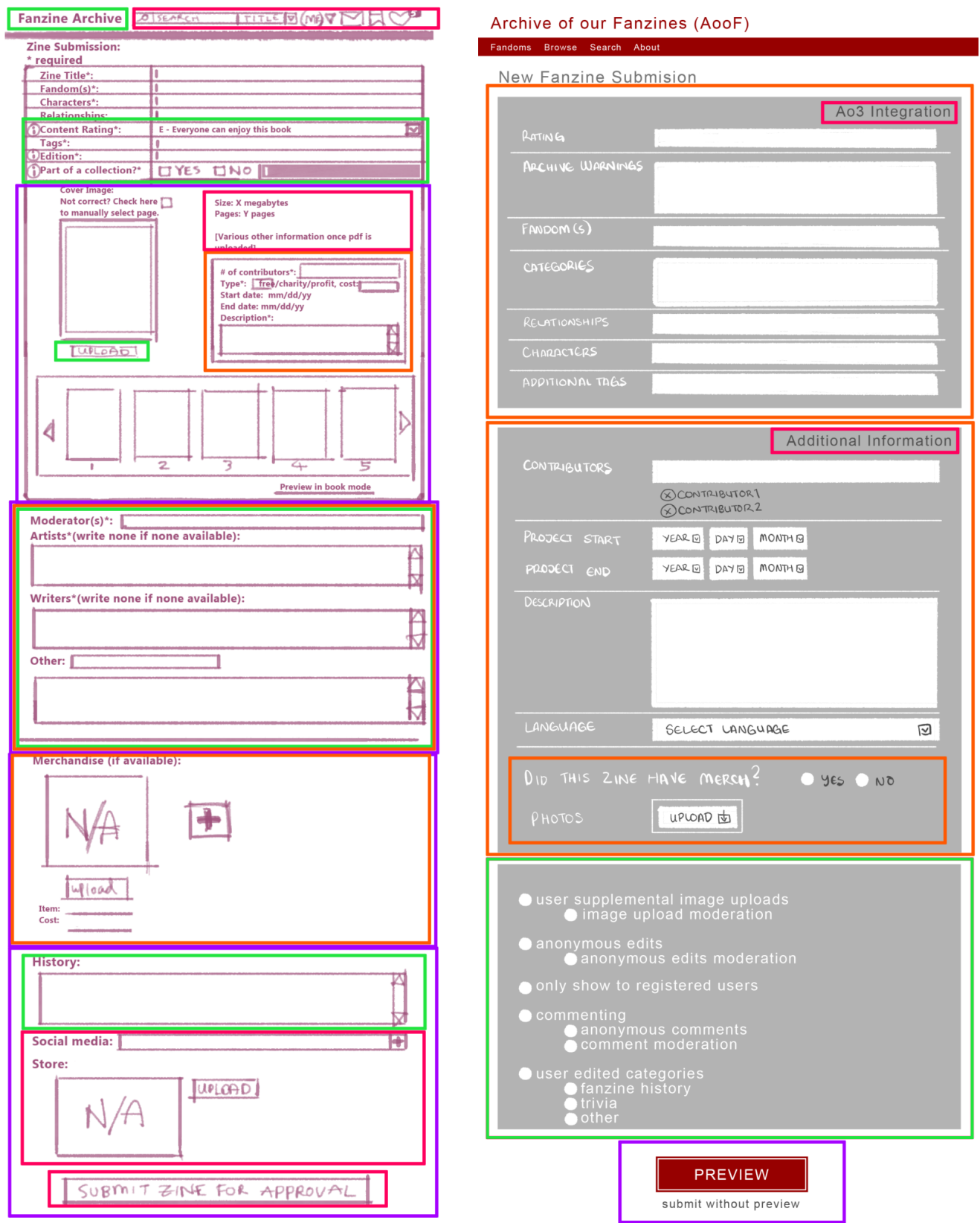

Fig. 3. Annotated comparison of two different stages of the "Telephone Game"

authorship can be singular, multiple (two or more coauthors), or even have none at all (via their "orphan works" function). Authors can also attribute their work to others, or even will it to a fannish next-of-kin should the original author die. Conversely, fanzines don't have authors. Fanzines have moderators and contributors, and the definitions of those roles shifts across projects. A single 
individual can simultaneously be a moderator and a contributor, while contributors might be writers, artists, or some other creative role. Delving deeper only complicates the matter further. For instance, if a fanzine has no author, it begs the question of who should be allowed to submit the artifact at all. This, in turn, ties directly into questions about permissions and credit, and the tension between upholding fanartist social norms and technical limitation.

Our participants quickly realized that the process of identifying, verifying, and receiving permission from every single contributor of every single fanzine was impossible-and furthermore, it was unnecessary. Due to their status as a product, individual contributors had already granted permission for the use of their pieces in the fanzine. The submission of a fanzine to the archive would be considered a "donation" of an artifact, which was within the permissions given by contributors during the initial project printing. Further breaking from the idea of fanzine authorship, the individual submitting would receive credit as the "donor" rather than the "author." This left the question of crediting individual moderators and contributors. Due to the fluid nature of identity in fandom spaces, the participants acknowledged that attempting to credit contributors externally to portfolios or blogs would simultaneously pose a verification nightmare and quickly leave the archive full of outdated and broken links. Instead, they proposed that moderator and contributor credits could be paired with their more specific role (i.e., "ModeratorName (shipping moderator)" or "ContributorName (illustrator)'), and then rolled into the tagging system.

Physicality and Merchandising. There are other aspects of fanzines that the current structure of AO3 was not well equipped to handle, such as the issue of physicality. Fanfiction archives so well because it does not lose value across clones and formats. Whether a fanfic is displayed on a smart phone or a laptop or a particularly smart refrigerator, the quality of the words and writing does not degrade with reproduction. Artwork is not nearly so flexible. Digital artifacts degrade as they're copied or edited. Good quality physical prints require knowledge, money, or both to acquire. A physical fanzine filled with professional prints loses significant value by virtue of being even a high-quality digital reproduction. This, unfortunately, is not something that our participants could or even expected to address in the co-design. Another item that is lost when focusing on archiving only digital PDFS is merchandise. Merchandise is a significant driving factor in fanzine sales, with most customers opting to pay extra for "bundles" that include not only the physical fanzine, but additional goodies like stickers, keychains, lanyards, and enamel pins. Current merchandise rivals and often excels the quality of official merchandise, using sturdier materials and greater artistic variation. However, while most fanzines credit merchandise designers in the fanzine itself, it is uncommon for them to include the designs themselves. A potential archive would lose a significant portion of fanzine history by assuming that the fanzines themselves are the only important artifacts to document.

Context and Process of Production. Finally, if we attempt to archive fanzines in isolation, we often lose the cultural and historical context of the piece. Many fanzines are usually made specifically in reaction to another event such as the end of a popular anime series, a natural disaster that requires charity donations, or a global pandemic that leaves artists trapped and bored in their own homes. While some of these instigators seem self-evident, others are more obscure or require a significant amount of context, such as fanzines that showcase "redrawn memes." While some of these contextual cues may be captured in the notes from the donor, or even described briefly in a forward, even this only brushes the surface. There are also times when the process itself might be worth archiving. For example, fanzine creative production is a highly involved community endeavor that can sometimes go horribly wrong; stories of internal drama, scams, and stolen money are unfortunately common. Should these incomplete fanzines find a home in the archive, the history of the failed production is of vital importance to giving context to the artifact. Unfortunately, due to 
the complexity of these situations, it would be difficult for one perspective to accurately record the events.

AO3 as a Point of Departure. As far as our co-design participants could tell, there were no analogous functions currently available within $\mathrm{AO} 3$ that might support these aspects of the fanzine community. Suggestions for managing merchandise included the additional of galleries containing photographs of these products. While the individual submitting the fanzine might have some of these photographs on hand, there is an equal chance that they do not; as a result, documenting these items would require some form of community outreach. This same outreach would be needed to provide additional information on a fanzine's historical and cultural context, as well as its production history. Because $\mathrm{AO} 3$ is not designed to support this type of community collaboration, our designers suggested taking a wiki-style approach, with specific sections of the artifact listing open to the public for (curated) edits.

\section{DISCUSSION}

Building on the results of our interview study and set of co-design activities, we have sought to describe the rich interactions and infrastructure of fanzine creation. In the following subsections, we seek to identify spaces where our findings intersect with current and future CSCW scholarship, focusing on: 1) issues of archiving in collaborative ways that respect shifting identities, technical limitations, and boundaries of fannish studies; 2) unique characteristics of mentorship and creative development outside of traditional "professional" spaces; and 3) intersections of monetary incentive, the "gift" culture of fanfic, and legal implications.

\subsection{Limitations of Archiving}

Our project demonstrates both a need and desire for the expansion of current fandom archival efforts to better capture visual artifacts, such as fanzines, which mirrors concerns regarding platform stability in the broader CSCW discourse (e.g., [30, 66]). Over the two-month project, our participants expressed their desire to protect their art from control or erasure by more powerful entities; to be acknowledged for their contributions to fandom; and to be legitimized in the eyes of the academic institution. The co-design activities provided not only a platform for them to articulate these desires, but empowered them in finding potential technical solutions that could exist beyond traditional "big tech," further illuminating concerns relating to identity and archiving of content that had both professional and personal meaning and value, presented previously by Lingel in relation to the drag community [66]. Even the selection of A03 as a point of departure represents the clash between the differing needs and infrastructure of fanartists as compared to other existing commercial platforms, particularly in relation to the ways in which existing platforms focus on commercialization and profit generation.

The technical limitations and opportunities suggested by our participants reveals new ways of considering issues of authorship, ownership, and public access in a proposed online platformbuilding upon issues raised by fanfic scholarship [43], but also diverging in key areas. In particular, the process and divergent outcomes of fanzine production reveals numerous opportunities to provide access and metadata for materials more commonly known "design precedent" in traditional design contexts [79]-a challenging area in curation that has infrequently been explored by CSCW scholars. The challenges of viewing fanzine artifacts as precedent relate both to the complex folksonomies that may describe the content of an individual fanzine, as well as the complex and layered ways in which creative traditions and team members align and diverse in relation to that fanzine over time. While some work in the CSCW tradition has addressed issues of remixing and ownership (e.g., [40]), the additional difficulties surrounding pseudonymous authorship, multiple 
artist identities, and a shifting legal landscape may reveal new opportunities for scholarly and technical engagement in this archival work. In addition, the collaborative and distributed nature of fanart interactions points towards more complex challenges to archive the richness of this work-far surpassing the polished and commercial outcomes of a graphic design community like Dribbble, but also pointing towards a heightened professionalism when compared to a creative art community such as DeviantArt. The implications for the technical infrastructure of such an archival effort are somewhat unclear, pointing towards the need for a flexible folksonomy such as used by $\mathrm{AO} 3$, but also a means of parsing communication and creative output across multiple members of a constantly evolving creative community which frequently shifts identities as well as collaborative partners.

While the development of a fanzine archive in the ways described by participants in Section 4.4.2 would begin to address several long-running needs in this community, it would also offer opportunities for expanding the role of fannish studies in CSCW scholarship, particularly in relation to fanart communities. Despite its close ties with fanfiction, our project demonstrated that fanart cannot be simply treated as "fanfiction, but pictures." Yet, there currently exists no other infrastructure by which to meaningfully study fanart communities, which are scattered across platforms and constantly at war with poor algorithms and content purges. Opportunities to engage both in the technical challenges presented by a fanzine archive and support scholarly engagement in the study of creative production in this context may build on unique strengths already available in the creation and study of creativity support tools in the CSCW tradition.

\subsection{Mentorship and Creative Development}

The distributed and often pseudonymous nature of creative interactions when creating a fanzine presents a number of potential considerations for supporting opportunities for mentorship, skill development, and even professionalization in a distributed creative community. As we have already alluded in the previous section, while the visual content of fanzine outputs might easily lead to comparisons of professional communication, networking, and skill development in professionalized visual design spaces on Reddit [19, 62], Dribbble [73], and DeviantArt [59], the social-yet-professional interactions among fanartists takes on a different character than traditional notions of professionalization. As our case studies have shown, the fanzine community is more than capable of the professional organization and management skills required to direct a complex international creative effort, and members of the community recognize the differing levels of skill and ability across a number of dimensions of competence. This distributed, organic, and pseudonymous community reveals new ways to consider notions of "professionalization" and competence that are often used to define and describe mentoring relationships. In contrast to these typical models of expertise, a wide range of creative, project management, manufacturing, and networking skills appear to be central to the success of each fanzine collaboration-perhaps even more intriguing given that the content of these partnerships is also highly creative, referencing sometimes niche and contested fannish interests. We propose that this model of distributed mentorship $[18,33,68]$ may allow further investigation of other forms of flexible professional interaction in other creative communities, revealing new opportunities for mentorship and creative development outside of traditional "professional" spaces.

\subsection{Monetary Incentives and Legal Concerns}

Although incremental improvements in legal oversight have emerged in the past two decades, fanworks are still a legal gray area. Fanfiction communities have historically responded to this by shielding their works with non-profit agreements and non-ownership disclaimers; however, fanzines do not share this social norm. The fanzine moderators we spoke to were well aware that 
their projects are "technically illegal," and instead of shrinking back, they've simply chosen to get smarter about how they conduct their business. Outside of announcement emails on social media, specific project interactions are mostly conducted in emails or private chat servers. Preorder periods are short, usually no longer than a month, and most projects rarely do more than a single print run. Once all the print fanzines are shipped, moderators do not restock their wares, project teams are dissolved, and private servers get deleted. Unless somebody is willing to part with their personal copy, once a project has ended that fanzine is essentially gone for good. All of these traits are simultaneously good business practices that drive up interest and sales with the promise of exclusivity, and fail-safes against corporate intervention.

Yet, while fanzines actively challenge the old fandom wisdom of not selling fanworks for profit, they also challenge attempts at the commercialization of fandom. While fanzines are undoubtedly a product, they are not designed with the intention of earning money. Rather, prices are intentionally set as close to production cost as possible and most of the contents of a fanzine are made available to the general public afterwards, with individual artists posting their pieces on social media or portfolios. The intention is accessibility, and the exclusivity of fanzines comes from the short window of availability, rather than financial elitism and gatekeeping.

Many fanzine projects also donate their excess funds to charity, but even the payout on for-profit fanzines is minimal when split among the contributors. When considering that some fanzine projects attract professional artists whose rates start in the \$100s of USD per hour, it becomes clear that despite the effort put into actually selling their product, financial gain is not the end goal.

As products, fanzines resist classic fandom wisdom cautioning against the sale of fanworks. However, when compared to corporate attempts to capitalize on the "free labor" of fans, it becomes clear that fanzines also help members to resist the commercialization of fandom and engage in a creative form of activism that seeks to be free from corporate control and censorship. This activist thread of creative production could bear comparison to creative subcultures in other contexts, such as machinima in relation to commercial video games [81] or critical design in relation to commercial design practices [4]. More scrutiny of the interplay of creative production, the boundary object of an often commercial storyline, and activism may reveal other opportunities to characterize creative engagement that exists beyond the commercial or professional.

\section{LIMITATIONS}

While we have been able to characterize and introduce fanzine production to the CSCW community in this paper, there are also important limitations to our work which we want to acknowledge. First, our engagement with fanzine creative production was mediated by the first author's historical relationship with this community across a range of production roles. While in an ethnographic sense, this closeness of relationship is of particular value (cf., the "expert researcher" role in [75]), it is possible that other roles or stances towards fanzine production could reveal other important sources of complexity that could expand our view of this creative production. Second, the nature of engagement and recruiting for both studies-particularly when framed by the pandemic-may have led to oversampling of particular perspectives or intersectional characteristics that were more immediately accessible to the first author. In acknowledging the complex, and often queer, identities taken on by people in the fanzine community, we also note that these identities also come with particular potential risks for participants. Thus, we are limited in our knowledge of what stories could not be told, which stories could put participants at risk if their fanzine identity was connected to their real-world identity, and what forms of diversity we were not able to supporteither intentionally or unintentionally-in our sampling and analysis process. These risks are not limited only to sample size, but also the unknown degree of diversity in the sample and potential suspicion around marginalized identity status (cf., [49]), which we have only begun to explore 
in this paper. Finally, we acknowledge that the goal of this paper is not to produce generalizable knowledge that applies to all fanzine communities or community members in a totalizing sense; in contrast, our goal was to produce a transparent and trustworthy account of some of the complexity that members of this community have faced in the wake of de-platforming, and the ways in which they have utilized ad hoc technology platforms to support their work. In this sense, our primary goal was to demonstrate how knowledge gained from these community members might transfer to other areas of concern in CSCW scholarship, and also provide a foothold for future research efforts in this creative production context.

\section{OPPORTUNITIES FOR FUTURE WORK}

In considering opportunities to explore the interactions among fanartists, we consider the three previous sections as potential lenses through which to further investigate fanzine creative practices, navigation of legal and creative issues in a distributed manner, and continuous mentorship and skill development that maintains the capability of this community over time. As a means of positioning this space for further research efforts, we rely upon the notion of "infrastructuring" as a means of foregrounding hidden aspects of the socio-technical infrastructure of a group, highlighting community norms, social connections, and the role of technology in supporting and sustaining these norms $[67,96]$. As we have demonstrated in this paper, transformative fandom exists almost entirely online, while also remaining independent of any specific technology or platform. As such, the internal infrastructuring of fandom and its creative communities is a continuous cycle of absorbing and appending technologies based on the tensions presented by creativity intersecting with "gray" legality, resulting in the shedding of technologies when they are no longer of use These flexible traits extend to fanzine creative communities, whose infrastructuring includes an ad hoc use of tools and networks, with few persistent boundary objects beyond the source of the art (e.g. characters, stories, etc.). This grants fanzine collaborations a high degree of flexibility in who, where, and how the projects roll out.

As such, we propose that fanzine engagement presents an opportunity to better study ad hoc assemblages of technology and social practices, whereby participatory engagement is used as a means of describing and promoting reflection on the infrastructure of the community. Future work could include the use of what Ludwig et al. [67] refer to as "resonance activities" that enable participants to better understand and reflect upon the socio-material infrastructure that supports their engagement. While some past disruptions in technology infrastructure have provoked change through violence to the fanart community (e.g., the Tumblr "porn ban"), we propose the use of reflective practices to better understand the constantly shifting infrastructure(s) of this distributed community, using probes and other participatory methods to tease out key social norms, values relating to tool selection, participatory roles, and means of connecting unstructured creative work to managed outputs. While we have used $\mathrm{AO} 3$ as a boundary object and point of departure in this paper, future work might focus on other aspects of distributed creative production, as we have proposed in the discussion section.

\section{CONCLUSION}

This research project, comprised of an interrelated interview study and set of co-design activites, explored the creative co-production of contemporary fanzines. Our findings expand upon the current academic understanding of fanart communities and their perpetual struggle to legitimize and legally protect their craft. In response to threats of censorship, we found that fanartists have taken up an attitude of "be gay, do crimes," reviving the production of fanzines as a way to create and preserve physical cultural artifacts. Building on the work of fanfiction communities, we propose the expansion of current fandom archival efforts to better include visual artifacts, using fanzines as

Proc. ACM Hum.-Comput. Interact., Vol. 5, No. CSCW2, Article 376. Publication date: October 2021. 
a starting point. We then discuss the unique challenges and benefits that might come with such as an endeavor, expand on the known differences between fanfiction and fanart culture, and explore alternative methods for creative co-production and mentorship in online communities.

\section{ACKNOWLEDGMENTS}

We gratefully acknowledge our participants, who contributed the hours of interviews and design research required to make this project a success. We also acknowledge the work of the Organization for Transformative Work, whose fandom advocacy efforts have provided the framework for the preservation and academic legitimization of fanworks and fannish history.

\section{REFERENCES}

[1] [n.d.]. History of Media Fanzines. https://fanlore.org/wiki/History_of_Media_Fanzines

[2] Camille Bacon-Smith. 1992. Enterprising women : television fandom and the creation of popular myth. University of Pennsylvania Press, Philadelphia.

[3] Shaowen Bardzell. 2010. Feminist HCI: taking stock and outlining an agenda for design (CHI '10). ACM, 1301-1310.

[4] Shaowen Bardzell, Jeffrey Bardzell, Jodi Forlizzi, John Zimmerman, and John Antanitis. 2012. Critical Design and Critical Theory: The Challenge of Designing for Provocation. In Proceedings of the Designing Interactive Systems Conference (Newcastle Upon Tyne, United Kingdom) (DIS '12). ACM, New York, NY, USA, 288-297. https://doi.org/ $10.1145 / 2317956.2318001$

[5] Chelsea Fay Baumgartner. 2019. Bodies of Knowledge: Politics of Archive, Disability, and Fandom. Canadian journal of disability studies 8, 2 (2019), 221-246.

[6] H. Russell Bernard. 2011. Interviewing: Unstructured and Semi-Structured. In Research Methods in Anthropology (5 ed.). AltaMira Press, Chapter 8, 156-186.

[7] H. Russell Bernard. 2011. Nonprobability Sampling and Choosing Informants. In Research Methods in Anthropology (5 ed.). AltaMira Press, Chapter 7, 143-155.

[8] Danah m Boyd and Nicole B Ellison. 2007. Social Network Sites: Definition, History, and Scholarship. Journal of computer-mediated communication: FCMC 13, 1 (Oct. 2007), 210-230. https://doi.org/10.1111/j.1083-6101.2007.00393.x

[9] Virginia Braun and Victoria Clarke. 2006. Using thematic analysis in psychology. Qualitative research in psychology 3 , 2 (2006), 77-101.

[10] Virginia Braun and Victoria Clarke. 2019. Reflecting on reflexive thematic analysis. Qualitative Research in Sport, Exercise and Health 11, 4 (Aug. 2019), 589-597. https://doi.org/10.1080/2159676X.2019.1628806

[11] Joseph Brennan. 2013. Slash manips: Remixing popular media with gay pornography. M/C fournal 16, 4 (2013).

[12] Lyndsay Brown. 2013. Pornographic Space-Time and the Potential of Fantasy in Comics and Fan Art. Transformative works and cultures 13 (2013), 39.

[13] Amy S Bruckman, Kurt Luther, and Casey Fiesler. 2015. When Should We Use Real Names in Published Accounts of Internet Research? In Digital research confidential : the secrets of studying behavior online, Eszter Hargittai and Christian Sandvig (Eds.). The MIT Press, Cambridge, Massachusetts, Chapter 11, 243-258.

[14] Julia Bullard. 2016. Motivating Invisible Contributions: Framing Volunteer Classification Design in a Fanfiction Repository. In GROUP '16 Proceedings of the 19th International Conference on Supporting Group Work. ACM, Sanibel Island, FL, USA, 181-193. https://doi.org/10.1145/2957276.2957295

[15] Julia Bullard. 2018. Curated Folksonomies: Three Implementations of Structure through Human Judgment. Knowledge organization 45, 8 (2018), 643-652.

[16] Catherine Burwell. 2015. You Know You Love Me: Gossip Girl fanvids and the amplification of emotion. Feminist Media Studies 15, 2 (2015), 306-323.

[17] Fabio Calefato, Giuseppe Iaffaldano, Filippo Lanubile, and Federico Maiorano. 2018. Investigating Crowd Creativity in Online Music Communities. Proc. ACM Hum.-Comput. Interact. 2, CSCW (Nov. 2018), 1-21. https://doi.org/10. $1145 / 3274296$

[18] Julie Campbell, Cecilia Aragon, Katie Davis, Sarah Evans, Abigail Evans, and David Randall. 2016. Thousands of Positive Reviews: Distributed Mentoring in Online Fan Communities. In Proceedings of the 19th ACM Conference on Computer-Supported Cooperative Work \& Social Computing - CSCW'16. ACM Press, New York, New York, USA, 689-702. https://doi.org/10.1145/2818048.2819934

[19] Ruijia Cheng, Maysnow Liu, Ziwen Zeng, and Steven P Dow. 2020. Critique Me: Exploring How Creators Publicly Request Feedback in an Online Critique Community. Proceedings of the ACM on Human-Computer Interaction 3 , CSCW (2020). https://programs.sigchi.org/cscw/2020/program/content/41581 
[20] Marjorie Cohee Manifold. 2009. What Art Educators Can Learn from the Fan-based Artmaking of Adolescents and Young Adults. Studies in Art Education 50, 3 (2009), 257-271.

[21] Francesca Coppa and Rebecca Tushnet. 2011. How to Suppress Women's Remix. Camera obscura (Durham, NC) 26, 2 (2011), 131-138.

[22] Crystal Rose Lending Library. [n.d.]. Crystal Rose Lending Library. https://crystalroselendinglibrary.com/

[23] Abigail De Kosnik. 2009. Should Fan Fiction Be Free? Cinema journal 48, 4 (2009), 118-124.

[24] Abigail De Kosnik. 2016. Rogue archives : digital cultural memory and media fandom. MIT Press, Cambridge, MA, USA. https://ieeexplore-ieee-org.ezproxy.lib.purdue.edu/book/7845160

[25] Michael A Devito, Ashley Marie Walker, Jeremy Birnholtz, Kathryn Ringland, Kathryn Macapagal, Ashley Kraus, Sean Munson, Calvin Liang, and Herman Saksono. 2019. Social Technologies for Digital Wellbeing Among Marginalized Communities. In Conference Companion Publication of the 2019 on Computer Supported Cooperative Work and Social Computing (Austin, TX, USA) (CSCW '19). Association for Computing Machinery, New York, NY, USA, 449-454. https://doi.org/10.1145/3311957.3359442

[26] Michaelanne Dye, Neha Kumar, Ari Schlesinger, Marisol Wong-Villacres, Morgan G Ames, Rajesh Veeraraghavan, Jacki O'Neill, Joyojeet Pal, and Mary L Gray. 2018. Solidarity Across Borders: Navigating Intersections Towards Equity and Inclusion. In Companion of the 2018 ACM Conference on Computer Supported Cooperative Work and Social Computing (Jersey City, NJ, USA) (CSCW'18). Association for Computing Machinery, New York, NY, USA, 487-494. https://doi.org/10.1145/3272973.3273007

[27] Brianna Dym, Jed Brubaker, and Casey Fiesler. 2018. "theyre all trans sharon": Authoring Gender in Video Game Fan Fiction. the international journal of computer game research 18, 3 (Dec. 2018). http://gamestudies.org/1803/articles/ brubaker_dym_fiesler

[28] Brianna Dym, Jed R. Brubaker, Casey Fiesler, and Bryan Semaan. 2019. "Coming Out Okay": Community Narratives for LGBTQ Identity Recovery Work. Proc. ACM Hum.-Comput. Interact. 3, CSCW, Article 154 (Nov. 2019 ), 28 pages. https://doi.org/10.1145/3359256

[29] Brianna Dym, Ruby Davis, Cecilia Aragon, Casey Fiesler, and Julia Bullard. 2018. Online Fandom: Boldly Going Where Few CSCW Researchers Have Gone Before. In CSCW 2018 Computer Supported Cooperative Work and Social Computing. ACM, Jersey City, NJ, USA. https://doi.org/10.1145/3272973.3274542

[30] Brianna Dym and Casey Fiesler. 2018. Generations, migrations, and the future of fandom's private spaces. Transformative works and cultures 28 (2018).

[31] Brianna Dym and Casey Fiesler. 2020. Ethical and privacy considerations for research using online fandom data. Transformative works and cultures 33 (June 2020). https://doi.org/10.3983/twc.2020.1733

[32] Escapade. [n.d.]. Escapade Zine Library. https://escapadecon.net/escapade-zine-library

[33] Sarah Evans, Katie Davis, Abigail Evans, Julie Ann Campbell, David P Randall, Kodlee Yin, and Cecilia Aragon. 2017. More Than Peer Production: Fanfiction Communities as Sites of Distributed Mentoring. In CSCW'17 Proceedings of the 2017 ACM Conference on Computer Supported Cooperative Work and Social Computing. 259-272. https: //doi.org/10.1145/2998181.2998342

[34] fanlore. [n.d.]. Fanzine Reading Room. https://fanlore.org/wiki/Fanzine_Reading_Room

[35] fanlore. [n.d.]. Open Letters to Star Wars Zine Publishers (1981). https://fanlore.org/wiki/Open_Letters_to_Star_ Wars_Zine_Publishers_(1981)

[36] fanlore. [n.d.]. The K/S Library. https://fanlore.org/wiki/The_K/S_Library

[37] fanlore. [n.d.]. The Snappening. https://fanlore.org/wiki/The_Snappening

[38] fanlore. [n.d.]. Timeline of Major Fandom Purges, Restrictions, and Hassles Regarding Fanworks and Their Content. https://fanlore.org/wiki/Timeline_of_Major_Fandom_Purges,_Restrictions,_and_Hassles_Regarding Fanworks_and_Their_Content

[39] Mark Fenster. 1993. Queer punk fanzines: Identity, community, and the articulation of homosexuality and hardcore. fournal of Communication Inquiry 17, 1 (1993), 73-94.

[40] Casey Fiesler and Amy S Bruckman. 2014. Remixers' understandings of fair use online. In Proceedings of the 17th ACM conference on Computer supported cooperative work \& social computing - CSCW'14. ACM Press, New York, New York, USA, 1023-1032. https://doi.org/10.1145/2531602.2531695

[41] Casey Fiesler and Amy S. Bruckman. 2019. Creativity, Copyright, and Close-Knit Communities: A Case Study of Social Norm Formation and Enforcement. Proceedings of the ACM on Human-Computer Interaction 3 (2019). Issue GROUP.

[42] Casey Fiesler and Brianna Dym. 2020. Moving Across Lands: Online Platform Migration in Fandom Communities. Proc. ACM Hum.-Comput. Interact. 4, CSCW1 (May 2020), 1-25. https://doi.org/10.1145/3392847

[43] Casey Fiesler, Shannon Morrison, and Amy S Bruckman. 2016. An archive of their own: A case study of feminist HCI and values in design. In Conference on Human Factors in Computing Systems - Proceedings. ACM, San Jose, California, USA, 2574-2585. https://doi.org/10.1145/2858036.2858409 
[44] Casey Fiesler, Shannon Morrison, R. Benjamin Shapiro, and Amy Bruckman. 2017. Growing Their Own: Legitimate Peripheral Participation for Computational Learning in an Online Fandom Community (CSCW' 17). ACM, 1375-1386.

[45] Diana Floegel. 2020. "Write the story you want to read": world-queering through slash fanfiction creation. Fournal of documentation 76, 4 (2020), 785-805.

[46] Electronic Frontier Foundation. 2019. What Tumblr's Ban on 'Adult Content' Actually Did. https://www.eff.org/ tossedout/tumblr-ban-adult-content

[47] Katharina Freund. 2016. "Fair use is legal use": Copyright negotiations and strategies in the fan-vidding community. New Media \& Society 18, 7 (2016), 1347-1363.

[48] Katharina Freund. 2018. Becoming a Part of the Storytelling. In A Companion to Media Fandom and Fan Studies. John Wiley \& Sons, Inc, Hoboken, NJ, USA, 207-223.

[49] Oliver L Haimson, Avery Dame-Griff, Elias Capello, and Zahari Richter. 2019. Tumblr was a trans technology: the meaning, importance, history, and future of trans technologies. Feminist media studies (2019), 1-17.

[50] Karen Hellekson. 2009. A Fannish Field of Value: Online Fan Gift Culture. Cinema fournal 48, 4 (2009), 27. https: //doi.org/10.1353/cj.0.0140

[51] Karen Hellekson. 2015. Making Use Of: The Gift, Commerce, and Fans. Cinema journal 54, 3 (2015), 125-131.

[52] Karen Hellekson and Kristina Busse. 2014. The Fan Fiction Studies Reader. University of Iowa Press, Iowa.

[53] Julie S Hui, Matthew W Easterday, and Elizabeth M Gerber. 2018. Distributed Apprenticeship in Online Communities. Human-Computer Interaction (May 2018), 1-51. https://doi.org/10.1080/07370024.2018.1469409

[54] Mizuko Ito. 2011. Machinima in a Fanvid Ecology. Fournal of Visual Culture 10, 1 (2011), 51-54.

[55] Gita Jackson. 2018. It Used To Be Perilous To Write Fanfiction. https://kotaku.com/it-used-to-be-perilous-to-writefanfiction-1826083509

[56] Henry Jenkins. 2013. Textual Poachers: Television Fans and Participatory Culture (updated twentieth anniversary ed. ed.). Routledge Ltd, London.

[57] Henry Jenkins. 2019. 'Art Happens not in Isolation, But in Community': The Collective Literacies of Media Fandom. Cultural Science Journal 11, 1 (2019), 78-88.

[58] Shannon Fay Johnson. 2014. Fan fiction Metadata Creation and Utilization within Fan Fiction Archives: Three Primary Models. Transformative works and cultures 17 (2014), 34.

[59] Brian L Jones. 2015. Collective Learning Resources: Connecting Social-Learning Practices in Deviantart to Art Education. Studies in Art Education 56, 4 (July 2015), 341-354. https://doi.org/10.1080/00393541.2015.11518975

[60] Maria Jose and John Tenuto. 2014. Spockanalia - The First Star Trek Fanzine. https://www.startrek.com/article/ spockanalia-the-first-star-trek-fanzine

[61] Nancy Kippax. 2008. Producing a Fanzine in the Before-Time - Reminisce With Me - LiveJournal. https://njpax. livejournal.com/3562.html

[62] Yubo Kou and Colin M Gray. 2017. Supporting Distributed Critique through Interpretation and Sense-Making in an Online Creative Community. Proceedings of the ACM on Human-Computer Interaction 1, CSCW (Dec. 2017), 60. https://doi.org/10.1145/3134695

[63] Steinar Kvale and Svend Brinkmann. 2008. Interview Variations (2 ed.). SAGE, 143-160.

[64] Shannon Liao. 2019. After the porn ban, Tumblr users have ditched the platform as promised. https://www.theverge. com/2019/3/14/18266013/tumblr-porn-ban-lost-users-down-traffic

[65] Yvonna S Lincoln and Egon G Guba. 1985. Doing What Comes Naturally. SAGE, 187-220.

[66] Jessa Lingel. 2017. Digital Countercultures and the Struggle for Community. MIT Press.

[67] Thomas Ludwig, Volkmar Pipek, and Peter Tolmie. 2018. Designing for Collaborative Infrastructuring: Supporting Resonance Activities. Proc. ACM Hum.-Comput. Interact. 2, CSCW (Nov. 2018), 1-29. https://doi.org/10.1145/3274382

[68] Kurt Luther and Amy Bruckman. 2008. Leadership in online creative collaboration. In Proceedings of the 2008 ACM conference on Computer supported cooperative work (San Diego, CA, USA) (CSCW'08). Association for Computing Machinery, New York, NY, USA, 343-352. https://doi.org/10.1145/1460563.1460619

[69] Kurt Luther, Jari-Lee Tolentino, Wei Wu, Amy Pavel, Brian P Bailey, Maneesh Agrawala, Björn Hartmann, and Steven P Dow. 2015. Structuring, Aggregating, and Evaluating Crowdsourced Design Critique. In CSCW'17: Proceedings of the 2017 ACM Conference on Computer Supported Cooperative Work and Social Computing (New York, NY). SIGCHI, ACM Special Interest Group on Computer-Human Interaction, New York, New York, USA, 473-485. https://doi.org/10. $1145 / 2675133.2675283$

[70] Haley Macleod, Ben Jelen, Annu Prabhakar, Lora Oehlberg, Katie Siek, and Kay Connelly. 2017. A Guide to Using Asynchronous Remote Communities (ARC) for Researching Distributed Populations. EAI Endorsed Transactions on Pervasive Health and Technology 3, 11 (2017). http://search.proquest.com/docview/2306319444/

[71] Marjorie Cohee Manifold. 2009. Fanart as craft and the creation of culture. International fournal of Education through Art 5, 1 (2009), 7-21. 
[72] Marjorie Cohee Manifold. 2013. Enchanting Tales and Imagic Stories: The Educational Benefits of Fanart Making. Art Education: Talking 66, 6 (2013), 12-19.

[73] Jennifer Marlow and Laura Dabbish. 2014. From rookie to all-star: professional development in a graphic design social networking site. In Proceedings of the 17th ACM conference on Computer supported cooperative work \& social computing. 922-933.

[74] Declan McCullagh. 2007. Mass deletion sparks LiveJournal revolt. https://www.cnet.com/news/mass-deletionsparks-livejournal-revolt/

[75] Nora McDonald, Sarita Schoenebeck, and Andrea Forte. 2019. Reliability and Inter-rater Reliability in Qualitative Research: Norms and Guidelines for CSCW and HCI Practice. Proc. ACM Hum.-Comput. Interact. 3, CSCW (Nov. 2019), 1-23. https://doi.org/10.1145/3359174

[76] N-Maulina. 2015. Tinker's Art Game. https://www.deviantart.com/n-maulina/art/Tinker-s-Art-Game-578442434

[77] National Library of Australia. [n.d.]. Susan Smith-Clarke Fanzine Collection. http://www.nla.gov.au/collect/sclarke.html

[78] Abby Ohlheiser. 2018. Before Tumblr announced plan to ban adult content, it was a safe space for exploring identity. https://www.washingtonpost.com/technology/2018/12/04/before-tumblr-banned-adult-content-it-wassafe-space-exploring-identity/

[79] Rivka Oxman. 1990. Prior knowledge in design: a dynamic knowledge-based model of design and creativity. Design Studies 11, 1 (Jan. 1990), 17-28. https://doi.org/10.1016/0142-694X(90)90011-Z

[80] Tyler Pace, Katie O’Donnell, Natalie DeWitt, Shaowen Bardzell, and Jeffrey Bardzell. 2013. From organizational to community creativity: paragon leadership \& creativity stories at etsy. In Proceedings of the 2013 conference on computer supported cooperative work. 1023-1034.

[81] Tyler Pace, Austin Toombs, Shad Gross, Tony Pattin, Jeffrey Bardzell, and Shaowen Bardzell. 2013. A tribute to Mad skill: expert amateur visuality and world of Warcraft Machinima. In Proceedings of the SIGCHI Conference on Human Factors in Computing Systems - CHI '13 (Paris, France). ACM Press, New York, New York, USA, 2019. https://doi.org/10.1145/2470654.2466267

[82] Michael Quinn Patton. 2001. Sampling Strategies (3 ed.). Sage, 243-244.

[83] Michael Quinn Patton. 2014. Qualitative research and evaluation methods: Integrating theory and practice (4th ed.) London, UK, Sage.

[84] Daniel Rees Lewis, Emily Harburg, Elizabeth Gerber, and Matthew Easterday. 2015. Building Support Tools to Connect Novice Designers with Professional Coaches. In Proceedings of the 2015 ACM SIGCHI Conference on Creativity and Cognition - C\&C '15. ACM Press, New York, New York, USA, 43-52. https://doi.org/10.1145/2757226.2757248

[85] Eli Rosenberg. 2018. Tumblr's nudity ban removes one of the last major refuges for pornography on social media. https://www.washingtonpost.com/business/2018/12/04/tumblrs-nudity-crackdown-means-pornography-willbe-harder-find-its-platform-than-nazi-propaganda/

[86] Johnny Saldaña. 2009. The coding manual for qualitative researchers. Sage, London; Thousand Oaks, Calif.

[87] Elizabeth B.-N Sanders and Pieter Jan Stappers. 2008. Co-creation and the new landscapes of design. CoDesign 4, 1 (2008), 5-18. http://www.tandfonline.com/doi/abs/10.1080/15710880701875068

[88] Gareth Schott and Andrew Burn. 2004. Art (re) production as an expression of collective agency within Oddworld Fan-culture. Works \& Days, Capitalizing on Play: Politicized Readings of the Computer Game Industry 22, 1 (2004), 251-274.

[89] Suzanne Scott. 2015. The Hawkeye Initiative: Pinning Down Transformative Feminisms in Comic-Book Culture through Superhero Crossplay Fan Art. Cinema journal 55, 1 (2015), 150-160.

[90] Burr Settles and Steven Dow. 2013. Let's get together: the formation and success of online creative collaborations. In Proceedings of the SIGCHI Conference on Human Factors in Computing Systems - CHI '13 (Paris, France). ACM Press, New York, New York, USA, 2009. https://doi.org/10.1145/2470654.2466266

[91] Jessica Seymour. 2018. Homage, Collaboration, or Intervention: How framing fanart affects its interpretation. Participations 15, 2 (2018), 98-114.

[92] Jessica Seymour. 2018. Racebending and Prosumer Fanart Practices in Harry Potter Fandom. In A Companion to Media Fandom and Fan Studies. John Wiley \& Sons, Inc, Hoboken, NJ, USA, 333-347.

[93] Pao Siangliulue, Kenneth C Arnold, Krzysztof Z Gajos, and Steven P Dow. 2015. Toward Collaborative Ideation at Scale-Leveraging Ideas from Others to Generate More Creative and Diverse Ideas. In CSCW'15 (New York, NY). ACM Press, 937-945. https://doi.org/10.1145/2675133.2675239

[94] Todd Spangler. 2020. Verizon Selling Tumblr to Company That Owns WordPress. https://variety.com/2019/digital/ news/verizon-sells-tumblr-automattic-wordpress-1203299860/

[95] Robert E. Stake. 2005. Qualitative Case Studies. In The SAGE Handbook of Qualitative Research (5 ed.), Norman K. Denzin and Yvonna S. Lincoln (Eds.). SAGE Publications, Chapter 17, 443-466. 
[96] Susan Leigh Star and Karen Ruhleder. 1996. Steps Toward an Ecology of Infrastructure: Design and Access for Large Information Spaces. Information Systems Research 7, 1 (March 1996), 111-134. https://doi.org/10.1287/isre.7.1.111

[97] Angelika Strohmayer, Janis Lena Meissner, Alexander Wilson, Sarah Charlton, and Laura McIntyre. 2020. "We come together as one...and hope for solidarity to live on": On Designing Technologies for Activism and the Commemoration of Lost Lives. In Proceedings of the 2020 ACM Designing Interactive Systems Conference (Eindhoven, Netherlands) (DIS '20). Association for Computing Machinery, New York, NY, USA, 87-100. https://doi.org/10.1145/3357236.3395452

[98] Texas A and M University Libraries. [n.d.]. Cushing Memorial Library and Archives. https://cushing.library.tamu.edu/

[99] The Starsky and Hutch Lending Library. 2007. The Starksy and Hutch Lending Library. https://www.squidge.org/ flamingo/library/index.htm

[100] Martin Tomitsch, Cara Wrigley, Madeleine Borthwick, Naseem Ahmadpour, A. Baki Kocaballi, Jessica Frawley, Claudia Núñez-Pacheco, Karla Straker, and Lian Loke. 2018. No Title. In Design. Think. Make. Break. Repeat. A Handbook of Methods. BIS, Amsterdam, Chapter Affinity Diagramming, 22-23.

[101] Austin Toombs, Shad Gross, Shaowen Bardzell, and Jeffrey Bardzell. 2017. From Empathy to Care: A Feminist Care Ethics Perspective on Long-Term Researcher-Participant Relations. Interacting with computers 29, 1 (Jan. 2017), 45-57. https://doi.org/10.1093/iwc/iww010

[102] Rebecca Tushnet. 2007. Payment in Credit: Copyright Law and Subcultural Creativity. Law and contemporary problems 70, 2 (2007), 135-174.

[103] Rebecca Tushnet. 2014. All of this has happened before and all of this will happen again: innovation in copyright licensing. Berkeley technology law journal 29, 3 (2014), 1447

[104] Rebecca Tushnet. 2014. "I'm a Lawyer, Not an Ethnographer, Jim”: Textual Poachers and Fair Use. Georgetown Law Faculty Publications and Other Works (2014).

[105] Rebecca Tushnet. 2015. The Romantic Author and the Romance Writer: Resisting Gendered Concepts of Creativity. Georgetown Law Faculty Publications and Other Works (2015).

[106] University of California Riverside. 2018. Eaton Collection at UC Riverside: Fanzine and Comic Book Collections. https://eaton.ucr.edu/fanzines.html

[107] University of Iowa. [n.d.]. Organization for Transformative Works Fanzine and Fan Fiction Collection.

[108] Kodlee Yin, Cecilia Aragon, Sarah Evans, and Katie Davis. 2017. Where No One Has Gone Before: A Meta-Dataset of the World's Largest Fanfiction Repository (CHI '17). ACM, 6106-6110.

[109] Robert K Yin. 2009. Designing Case Studies (4 ed.). SAGE, 25-65.

[110] Xuan Zhao, Cliff Lampe, and Nicole B Ellison. 2016. The Social Media Ecology: User Perceptions, Strategies and Challenges. In Proceedings of the 2016 CHI Conference on Human Factors in Computing Systems - CHI '16 (Santa Clara, California, USA). ACM Press, New York, New York, USA, 89-100. https://doi.org/10.1145/2858036.2858333

Received October 2020; revised April 2021; accepted July 2021 